\title{
Adaptive Axonal Remodeling in the Midbrain Auditory Space Map
}

\author{
William M. DeBello, ${ }^{1,2}$ Daniel E. Feldman, ${ }^{3}$ and Eric I. Knudsen ${ }^{1}$ \\ ${ }^{1}$ Department of Neurobiology, Sherman Fairchild Sciences Building, Stanford University School of Medicine, Stanford, California \\ 94305-5125, 2Center for Neuroscience, Department of Neurobiology, Physiology and Behavior, University of California-Davis, \\ Davis, California 95616, and 32Department of Biology, University of California-San Diego, La Jolla, California 92093
}

The auditory space map in the external nucleus of the inferior colliculus (ICX) of barn owls is highly plastic, especially during early life. When juvenile owls are reared with prismatic spectacles (prisms) that displace the visual field laterally, the auditory spatial tuning of neurons in the ICX adjusts adaptively to match the visual displacement. In the present study, we show that this functional plasticity is accompanied by axonal remodeling.

The ICX receives auditory input from the central nucleus of the inferior colliculus (ICC) via topographic axonal projections. We used the anterograde tracer biocytin to study experiencedependent changes in the spatial pattern of axons projecting from the ICC to the ICX. The projection fields in normal adults were sparser and more restricted than those in normal juveniles. The projection fields in prism-reared adults were denser and broader than those in normal adults and contained sub- stantially more bouton-laden axons that were appropriately positioned in the ICX to convey adaptive auditory spatial information. Quantitative comparison of results from juvenile and prism-reared owls indicated that prism experience led to topographically appropriate axonal sprouting and synaptogenesis. We conclude that this elaboration of axons represents the formation of an adaptive neuronal circuit.

The density of axons and boutons in the normal projection zone was preserved in prism-reared owls. The coexistence of two different circuits encoding alternative maps of space may underlie the ability of prism-reared owls to readapt to normal conditions as adults.

Key words: axon elaboration; axon elimination; anterograde tracing; biocytin; boutons; development; experience-dependent plasticity; inferior colliculus; synaptogenesis; topographic map
Experience customizes the brain to suit the unique needs and environment of the individual. Whether such adaptive plasticity involves anatomical remodeling has profound implications for underlying mechanisms. In several systems, anatomical changes have been demonstrated as a result of deprivation or denervation (for review, see Buonomano and Merzenich, 1998). In these cases, the anatomical changes are thought to result from the experimentally induced imbalance in activity between competing afferent channels. To determine whether axonal remodeling occurs in response to more subtle manipulations of experience, we searched for changes in axonal morphology associated with adaptive plasticity of the barn owl auditory space map.

The auditory space map is derived from cues that result from the interaction of incoming sounds with the head and ears. In barn owls, the principal cue for azimuth is interaural time difference (ITD) (Moiseff and Konishi, 1981; Olsen et al., 1989). Neurons in the owl's auditory system are tuned for particular values of ITD and are arranged to form topographic maps, which occur in the central nucleus of the inferior colliculus (ICC), the external nucleus of the inferior colliculus (ICX), and the optic tectum (OT) (Fig. 1). ITD information is relayed serially through these structures via topographic projections (Knudsen and Knud-

Received Oct. 25, 2000; revised Feb. 16, 2001; accepted Feb. 23, 2001.

This study was supported by a grant from the National Institute on Deafness and Other Communication Disorders, National Institutes of Health R01-DC00155-19, a McKnight Senior Investigator Award to E.I.K., and a National Research Service Award to W.M.D. We thank P. Knudsen for technical assistance, K. Cheng and P. Knudsen for axon tracing, and all members of the Knudsen lab for helpful comments on this manuscript.

Correspondence should be addressed to W. M. DeBello, Center for Neuroscience, 1544 Newton Court, Davis, CA 95616. E-mail: wmdebello@ucdavis.edu. Copyright (C) 2001 Society for Neuroscience $0270-6474 / 01 / 213161-14 \$ 15.00 / 0$ sen, 1983; Wagner et al., 1987). In the OT, the auditory space map aligns and integrates with a visual space map (Fig. 1).

The registration of the auditory and visual space maps in the OT is influenced by experience (Knudsen, 1983; King et al., 1988; Knudsen and Brainard, 1991), as has been demonstrated by rearing juvenile owls with prisms that displace the visual field horizontally. Prisms do not alter the ITDs experienced by an owl but instead alter the locations in the visual field to which particular ITDs correspond. After several weeks of prism experience, the ITD tuning of neurons in the OT changes by an amount and in a direction predicted by the prismatic displacement (Fig. 1C). Because a major role of the OT is to guide orienting movements toward sounds (Knudsen et al., 1993; Stein and Meredith, 1993), these adaptive changes in ITD tuning are accompanied by adaptive changes in auditory orienting behavior (Knudsen and Knudsen, 1990).

Prism-induced adjustments in ITD tuning occur in the OT and ICX but not in the ICC (Brainard and Knudsen, 1993), which provides the major source of auditory input to ICX. Therefore, it has been proposed (Brainard and Knudsen, 1993; Feldman and Knudsen, 1997) that one mechanism underlying adaptive plasticity is a systematic remapping of the axonal projection from the ICC to the ICX (Fig. 1C). Using retrograde tracing techniques, Feldman and Knudsen (1997) found evidence that supports this hypothesis. One caveat in interpreting these results, however, is that retrograde labeling can covary with the functional strength of synapses (Holtzman et al., 1971; Jiang et al., 1993). It is possible, therefore, that the altered topography of retrogradely labeled neurons in the ICC of prism-reared owls reflects changes in synaptic strengths that occur within an unchanged, broad, axonal projection. Because this issue is crucial to further investigation, 
Figure 1. The midbrain sound localization pathway. $A$, Ascending ITD information is represented in frequency-specific channels within the ICC. It is relayed from the ICC to the ICX where it is combined across frequency channels and with other auditory cues to form a map of auditory space. This map is relayed to the OT where it merges with a visual space map derived from retinal input and input from the forebrain. $B$, Lateral view of a barn owl brain showing the horizontal plane of section through the midbrain. $C$, Hypothesis for adaptive axonal remodeling in the midbrain auditory space map. These are horizontal sections through the right optic lobe in a normal (left panel) and prism-reared (right panel) owl. The ITD tuning of neurons is indicated by numbers in the ICC and OT: i20 indicates ipsilateral-leading $20 \mu \mathrm{sec}$ (i.e., rightear leading on the right side of the brain), and c20 indicates contralateral-leading $20 \mu \mathrm{sec}$. In all structures, ipsilateral-leading ITDs are represented rostrally, and contralateral-leading ITDs are represented progressively more caudally. Iso-ITD contours are indicated by thin lines. Spatially restricted axonal projections from the ICC to the ICX are indicated by thick arrows; spatially restricted axonal projections from the ICX to the OT are not shown. Normally, a sound producing an ITD of c20 $\mu$ sec originates at contralateral $8^{\circ}$ in the owl's visual field. During prism rearing, owls experience a chronic displacement of the visual field, as indicated by the dashed lines in the right panel. For instance, a visual stimulus at $c 8^{\circ}$ activates neurons at an abnormally rostral location in the OT, one that normally responds optimally to an ITD of i20 $\mu$ sec. After several weeks of prism experience, however, this location responds optimally to an ITD of $\sim \mathrm{c} 20 \mu \mathrm{sec}$. A comparable shift in ITD tuning also occurs in the ICX, but no shift occurs in the ICC, suggesting that the ICC-ICX axonal projection is adaptively remodeled (thick arrows, right panel).

we have directly addressed it by using anterograde labeling techniques.

\section{MATERIALS AND METHODS}

Anatomical tracing and physiological mapping was performed in 17 barn owls (Tyto alba): 5 normal juveniles, 5 normal adults, and 7 prism-reared adults. The age and experience of each owl are given in Table 1. During all procedures, the owls were provided for in accordance with the National Institutes of Health Guide for the Care and Use of Laboratory Animals and the Guidelines of the Stanford University Institutional Animal Care and Use Committee.

Prism rearing. Owls were raised in brooding boxes with their siblings until $\sim 60 \mathrm{~d}$. At this age, the facial ruff has reached adult size and the skull has hardened. For surgical attachment of headgear, the owl was anesthetized with $2 \%$ halothane in nitrous oxide/oxygen (4:5), the scalp was cleaned with betadine solution, and the skull was exposed. A mount for the prisms was cemented to the front of the skull with dental acrylic, and a small plate for securing the head in the recording apparatus was cemented to the back of the skull. Surgical incisions were treated with betadine, sutured, and infused with lidocaine hydrochloride. Owl ringer ( $2 \mathrm{cc} ; 2.5 \%$ dextrose in $0.75 \%$ saline) was administered via intramuscular injection, and the owl was allowed to recover overnight before being released into a large flight room.

Prisms were constructed by mounting Fresnel prismatic lenses (40 diopters, Vision Care/3M) in lightweight metal frames. These prisms shifted the visual field by $23^{\circ}$, either to the right or the left, and displaced a region of the visual field measuring $45-60^{\circ}$ in azimuth and $45-55^{\circ}$ in elevation (Brainard and Knudsen, 1993). The peripheral visual field was occluded by the prism frames.

Usually prisms were mounted at $\sim 60 \mathrm{~d}$, but in three cases they were mounted at older ages (Table 1). After 6-8 weeks of prism experience in the flight room, the ITD tuning of neurons in the OT and ICX had shifted in the direction predicted by the prismatic displacement of the visual field. ITD tuning was measured as described below. In all but one case $(\mathrm{MnL})$, a complete shift of ITD tuning was allowed to occur before anatomical experiments were performed (Table 1).
Electrophysiology. On the day of an experiment, the owl was anesthetized as before, placed in a soft leather restraint, and bolted in the stereotaxic recording apparatus. Craniotomies were opened over the optic tectum and inferior colliculus based on stereotaxic coordinates. For the duration of the experiment, the owl was maintained under nitrous oxide/oxygen (4:5), and halothane was applied briefly only if the owl became active. Epoxylite-coated tungsten electrodes (0.3-2 M $\Omega$ ) were lowered through the forebrain into the structures of interest. The surface of the brain was periodically irrigated with chloramphenicol solution $(0.5 \%)$. At the end of a recording session, the craniotomies were inf used with chloroptic ointment $(1 \%)$ and sealed with dental acrylic, and the owl was placed in a recovery box overnight. In the morning, the owl was returned to its home flight room.

Multiunit responses were recorded extracellularly. A level discriminator was used to isolate action potentials generated by a small number of neurons at each recording site. The timing of all action potentials, relative to stimulus onset, was stored on a computer. Individual recording sites were separated by a minimum of $400 \mu \mathrm{m}$ dorsoventrally and $200 \mu \mathrm{m}$ mediolaterally or rostrocaudally.

Auditory measurements. Acoustic stimuli were generated digitally and presented dichotically through earphones (Knowles ED-1941) coupled to damping assemblies (BF-1743). To calibrate the earphones, sound output was measured with Bruel and Kjaer condenser microphones and analyzed with a spectrum analyzer. The stimulus waveforms were adjusted to equalize the amplitude and phase spectra of the earphones to within $\pm 2 \mathrm{~dB}$ and $\pm 2 \mu \mathrm{sec}$, respectively. Earphones were placed in the ear canals $\sim 5 \mathrm{~mm}$ from the tympanic membrane. All stimuli were $50 \mathrm{msec}$ in duration and presented at an average binaural level of $20 \mathrm{~dB}$ above auditory threshold. Stimuli were either broad-band noise $(0 \mathrm{msec}$ rise/fall times), high-pass-filtered at $3 \mathrm{kHz}$ to minimize propagation through the interaural canal (Moiseff and Konishi, 1981), or tones (5 msec rise/fall times).

Auditory responses were defined as the number of action potentials occurring during the $50 \mathrm{msec}$ acoustic stimulus minus the number occurring in the $50 \mathrm{msec}$ preceding the stimulus. To assess ITD tuning, ITD was varied in $10-20 \mu \mathrm{sec}$ increments over a range of $100-600 \mu \mathrm{sec}$, 


\begin{tabular}{|c|c|c|c|c|c|c|c|c|}
\hline Owl & $\begin{array}{l}\text { Age at } \\
\text { injection }\end{array}$ & $\begin{array}{l}\text { Age at prism } \\
\text { attachment }\end{array}$ & $\begin{array}{l}\text { Days with } \\
\text { prisms }\end{array}$ & $\begin{array}{l}\text { Shift in } \\
\text { OT }\end{array}$ & $\begin{array}{l}\text { Side of } \\
\text { brain }\end{array}$ & $\begin{array}{l}\text { Prism } \\
\text { direction }\end{array}$ & $\begin{array}{l}\text { Adaptive } \\
\text { direction }\end{array}$ & $\begin{array}{l}\text { Injection site } \\
\text { (ITD) }\end{array}$ \\
\hline \multicolumn{9}{|c|}{ Normal adults } \\
\hline McR & $>245$ & & 0 & & $\mathrm{R}$ & & & c18 \\
\hline $\mathrm{KgL}$ & 373 & & 0 & & $\mathrm{~L}$ & & & $\mathrm{c} 45$ \\
\hline HyL & $>365$ & & 0 & & $\mathrm{~L}$ & & & $\mathrm{c} 16$ \\
\hline TrR & 2920 & & 0 & & $\mathrm{R}$ & & & $\mathrm{c} 20$ \\
\hline EfR & 240 & & 0 & & $\mathrm{R}$ & & & $\mathrm{c} 20$ \\
\hline \multicolumn{9}{|c|}{ Normal juveniles } \\
\hline TnR & 55 & & 0 & & $\mathrm{R}$ & & & $\mathrm{c} 23$ \\
\hline TnL & 55 & & 0 & & $\mathrm{~L}$ & & & $\mathrm{c} 22$ \\
\hline FkL & 58 & & 0 & & $\mathrm{R}$ & & & c19 \\
\hline DnL & 55 & & 0 & & $\mathrm{~L}$ & & & c30 \\
\hline YgL & 60 & & 0 & & $\mathrm{~L}$ & & & $\mathrm{c} 20$ \\
\hline NnR & 60 & & 0 & & $\mathrm{R}$ & & & $\mathrm{c} 22$ \\
\hline $\mathrm{NnL}$ & 60 & & 0 & & $\mathrm{~L}$ & & & $\mathrm{c} 17$ \\
\hline \multicolumn{9}{|c|}{ Prism-reared } \\
\hline $\mathrm{PhL}$ & 145 & 105 & 40 & 41 & $\mathrm{~L}$ & $\mathrm{R} 23$ & Caudal & $\mathrm{c} 20$ \\
\hline $\mathrm{BcR}$ & 553 & 60 & 493 & 40 & $\mathrm{R}$ & R23 & Rostral & $\mathrm{c} 20$ \\
\hline $\mathrm{HzL}$ & 299 & 65 & 234 & 45 & $\mathrm{~L}$ & L23 & Rostral & $\mathrm{c} 40$ \\
\hline DsL & 591 & 57 & 534 & 46 & $\mathrm{~L}$ & $\mathrm{R} 23$ & Caudal & $\mathrm{c} 10$ \\
\hline DsR & 591 & 57 & 534 & 63 & $\mathrm{R}$ & $\mathrm{R} 23$ & Rostral & $\mathrm{c} 45$ \\
\hline $\mathrm{TtR}$ & 285 & 104 & 181 & 35 & $\mathrm{R}$ & L23 & Caudal & $\mathrm{c} 20$ \\
\hline LdR & 338 & 65 & 273 & 42 & $\mathrm{R}$ & $\mathrm{R} 23$ & Rostral & $\mathrm{c} 20$ \\
\hline $\mathrm{MnL}$ & 120 & 103 & 17 & 0.7 & $\mathrm{~L}$ & L23 & & c16 \\
\hline
\end{tabular}

Ages in days. ITD is in microseconds.

between $300 \mu \mathrm{sec}$ left-ear leading and $300 \mu \mathrm{sec}$ right-ear leading. ITDs were presented 10-50 times in a random interleaved order, with an interstimulus interval of $1 \mathrm{sec}$, and at the best interaural level difference (ILD) measured at the site. The best ILD was determined at a fixed ITD that was within $\pm 10 \mu \mathrm{sec}$ of the most effective ITD. ILD was varied over a range of $30 \mathrm{~dB}$ in increments of $3-5 \mathrm{~dB}$. ITD tuning width was defined as the range of ITDs that elicited at least $50 \%$ of the maximum response for the site, and the best ITD was defined as the midpoint of that range. Frequency tuning was determined by presenting tones varying from 2 to $10 \mathrm{kHz}$ in increments of $1 \mathrm{kHz}$, using the best ITD and best ILD for the site. Frequency tuning width was defined as the range of frequencies that elicited at least $50 \%$ of the maximum response, and best frequency was defined as the midpoint of this range.

Stimulation and acquisition were controlled using the SOUND program (J. Gold, University of Washington).

Physiological mapping of the OT, ICX, and ICC. Maps of ITD exist in the ICC, ICX, and OT. In each of these structures, ITD is mapped principally along the rostral-caudal axis (Fig. $1 C$ ). The OT was identified by characteristic bursting activity in the superficial layers and by the presence of strong visual responses. Visual receptive fields (vrfs) were measured by projecting light stimuli onto a calibrated globe or tangent screen. ITD tuning in the OT is typically sharp (width $\sim 20-30 \mu \mathrm{sec}$ ), with a single peak over a large range of ITDs. In each owl, ITD tuning was measured at a number of sites representing frontal space $\left( \pm 20^{\circ}\right.$ azimuth, from $+10^{\circ}$ to $-20^{\circ}$ elevation) and from all layers of the OT. Normally, best ITD varies linearly with the azimuth of the vrf according to the following formula: best ITD $(\mu \mathrm{sec})=2.5 *$ vrf azimuth (degrees). For each site, the shift in ITD tuning away from normal was calculated as ITD tuning shift $=$ best ITD $-2.5 *$ vrf azimuth.

The ICX was identified by the absence of visual responses, short latency $(<9 \mathrm{msec})$ phasic or phasic/tonic auditory responses, broad tuning for frequency (width $>2.4 \mathrm{kHz}$ ), ITD tuning curves with substantial side peaks ( $>50 \%$ of the amplitude of the main peak), corresponding to equivalent interaural phases of the best frequency, ILD tuning, and a progression of best ILDs along the dorsoventral axis of the nucleus.

The ICC was distinguished from the ICX by the similar height of interaural phase equivalent peaks in the ITD tuning curves, short latency responses ( $\sim 5 \mathrm{msec}$ ), which tend to be tonic, poor ILD tuning, narrow frequency tuning (width $<2.4 \mathrm{kHz}$ ), and a systematic progression of best frequency, from low to high along the dorsoventral axis of the nucleus.
Biocytin injections. Biocytin was injected at the representation of contralateral-ear-leading $20 \mu \mathrm{sec}(\mathrm{c} 20 \mu \mathrm{sec})$, in the $6 \mathrm{kHz}$ frequency lamina of the ICC. This location was chosen for two reasons. First, it is in the middle of the portion of the ITD map that is reliably shifted by prism experience. Second, the representations of c20 $\mu \mathrm{sec}$ in the ICC and ICX occur at the same rostrocaudal level of the tectal lobe (Brainard and Knudsen, 1993; Gold and Knudsen, 2000), which facilitates quantification of the ICC-ICX axonal projection (discussed below). In a few cases, injections were targeted at the representation of 0 or c $45 \mu$ sec (Table 1). In one case $(\mathrm{KgL})$, biotinylated dextran amine was used as the anterograde tracer. Because this case was indistinguishable from the other adult cases, it was included in the analysis.

For injection, a 5\% solution of biocytin in $0.76 \%$ saline was freshly prepared. Thin-walled, fiber-filled borosilicate glass $(1.5 \mathrm{~mm})$ was pulled on a vertical puller. The electrode tip was broken to an inner diameter of $15 \mu \mathrm{m}$. The surface of the brain was cleaned with chloramphenicol solution $(0.5 \%)$ and dried. The electrode was filled with the biocytin solution and lowered to the targeted site. Multiunit activity was recorded through the electrode with a silver wire. ITD and frequency tuning were used to position the electrode. Biocytin was iontophoresed by passing 3 $\mu \mathrm{A}$ of positive current from a constant current source (Grass SIU) with a $50 \%$ duty cycle ( $7 \mathrm{sec}$ on/off) for $15 \mathrm{~min}$. Iontophoresis was terminated if the current dropped below $3 \mu \mathrm{A}$, indicating clogging of the tip. After each successful injection, ITD and frequency tuning were reassessed to confirm that the neurons at the injection site were tuned to the same values as measured before the injection. The electrode was left in place for $15 \mathrm{~min}$ and then was withdrawn slowly to the top of the ICX.

Visualization of labeling. After 12-16 hr of survival, the owl was deeply anesthetized with 5\% halothane and nitrous oxide/oxygen (4:5). The thoracic cavity was opened and Nembutal $(30 \mathrm{mg} / \mathrm{kg})$ was injected into the liver. Heparin $(300 \mathrm{U})$ was injected into the left ventricle, and the owl was perfused transcardially with $500 \mathrm{ml}$ of $0.1 \mathrm{M}$ phosphate buffer (PB) containing lidocaine $(3 \mathrm{ml} / \mathrm{l})$, followed by $500 \mathrm{ml}$ of $4 \%$ paraformaldehyde in PB, followed by $200 \mathrm{ml}$ of $4 \%$ paraformaldehyde in PB with $10 \%$ sucrose. The brain was removed and sunk in $4 \%$ paraformaldehyde in PB with $30 \%$ sucrose.

After 3-7 d, $40 \mu \mathrm{m}$ sections were cut though the midbrain in the horizontal plane defined by the long axis of the OT (Fig. $1 B$ ). Sections were cut on a freezing microtome and stored at $4^{\circ} \mathrm{C}$ overnight in $\mathrm{PB}$. Two-thirds of the sections were reacted with an antibody to biocytin, and 
every third section was reacted with an antibody to a calcium binding protein $(\mathrm{CaBP})$, which labels the core region, a subdivision of the ICC, and the lateral rim of the ICX (Takahashi et al., 1987). The antibody (7E4 F2) was provided by Dr. C. E. Carr (University of Maryland). Staining of the ICC core served as an anatomical marker for determining the boundary between the ICC and the ICX (Fig. 2).

To visualize biocytin labeling and $\mathrm{CaBP}$ staining, an avidin-biotin$\mathrm{DAB}$ reaction was used. The biocytin protocol was as follows. Endogenous peroxidases were quenched in $10 \%$ methanol and $1 \% \mathrm{H}_{2} \mathrm{O}_{2}$ in $\mathrm{PB}$ for $30 \mathrm{~min}$. Sections were rinsed in $\mathrm{PB}$, incubated for $1 \mathrm{hr}$ in blocking serum (1\% normal rabbit serum, $0.75 \%$ Triton $X-100$ in PB), rinsed in $\mathrm{PB}$, and incubated in a solution of goat anti-biotin (1:5000) in $1 \%$ normal rabbit serum and $0.1 \%$ Triton $\mathrm{X}-100$ in $\mathrm{PB}$ for a period of $1-2 \mathrm{hr}$ at room temperature, and then at $4^{\circ} \mathrm{C}$ overnight. The next day, sections were rinsed in $\mathrm{PB}$ and incubated in biotinylated anti-goat antibody (1:1500) for $1 \mathrm{hr}$, rinsed in $\mathrm{PB}$, and incubated sequentially in solutions of avidin and biotin-peroxidase complex (Vector Laboratories, Burlingame, CA) for 1 $\mathrm{hr}$ each. Sections were rinsed in $\mathrm{PB}$ and Tris-imidazole buffer, developed for $10-20 \mathrm{~min}$ in $0.05 \% \mathrm{DAB}$ and $0.003 \% \mathrm{H}_{2} \mathrm{O}_{2}$ in Tris-imidazole buffer, mounted on Superfrost Plus slides, dehydrated, and cleared in xylenes for several hours. Labeling was greatly enhanced by using a silver/gold intensification reaction (Kitt et al., 1988). Mounted sections were rehydrated, incubated in $1.42 \%$ silver nitrate at $56^{\circ} \mathrm{C}$ for $1 \mathrm{hr}$, rinsed in running $\mathrm{dH}_{2} \mathrm{O}$ for $10 \mathrm{~min}$, incubated in $0.2 \%$ gold chloride at room temperature for $10 \mathrm{~min}$, rinsed in $\mathrm{dH}_{2} \mathrm{O}$ for $10 \mathrm{~min}$, fixed in $5.0 \%$ sodium thiosulfate for $5 \mathrm{~min}$, rinsed in running $\mathrm{dH}_{2} \mathrm{O}$, dehydrated, cleared in xylenes, and coverslipped with Permount.

The $\mathrm{CaBP}$ protocol was similar to the biocytin protocol with the following modifications: blocking serum was normal horse serum, $4 \%$ in $0.4 \%$ Triton $\mathrm{X}-100,1 \%$ bovine serum albumin (BSA) in PB; primary was a mouse anti-CaBP antibody, $1: 2000$ in $0.4 \%$ Triton $X-100,1 \%$ BSA in $\mathrm{PB}$; and the secondary was a biotinylated anti-mouse antibody, 1:1500 in $0.02 \%$ Triton X-100, $1 \%$ BSA in PB.

Analysis of axons and boutons. The spatial patterns of biocytin-labeled fibers and boutons were assessed by high-resolution light microscopy. Image acquisition and analysis were performed using a Nikon Eclipse E800 microscope, SPOT digital camera (Diagnostic Instruments, Inc.), and Simple32 image processing software (Compix, Inc.). All images were obtained with the section oriented parallel to the rostral-caudal axis, defined by the midline of the brain. To determine the location of the border between the ICC and the ICX, low-power $(2 \times$ objective) images of each biocytin section and adjacent $\mathrm{CaBP}$ section were digitally superimposed. The position of the darkly stained core region in the CABP section was transferred onto the biocytin image (Fig. 2). Previous work has estimated the border between the ICC and the ICX as $600 \mu \mathrm{m}$ from the lateral edge of core (Takahashi et al., 1987; Brainard and Knudsen, 1993; Feldman and Knudsen, 1997). Once this border was determined, digital images $(1280 \times 1024$ pixels $)$ of the biocytin labeling within the ICX were collected using a $10 \times$ objective. For each section, multiple image fields, which together spanned the rostrocaudal extent of the ICX, were collected. For each field, images were collected at five separate focal planes, spanning the depth of section, and then were combined into one image using minimal value superposition (biocytin labeling is dark relative to the background of the section). The resultant high-resolution images (Fig. 2) were used for axon tracing.

Axons were digitally traced by an observer (K. Cheng or P. Knudsen) who was unaware of the case history of the owl. All of the axons that extended into the ICX were traced regardless of whether they bore boutons. Boutons were identified as punctate swellings of labeled axons.

To obtain spatial distributions of axonal lengths and bouton number, the ICX was subdivided into zones oriented orthogonally to the rostrocaudal axis (Fig. 3). Each zone was $160 \mu \mathrm{m}$ in rostrocaudal extent, which corresponds to $\sim 5 \%$ of the rostrocaudal extent of ICX. The rostral and caudal poles of the ICX were identified on the basis of CaBP staining (Takahashi et al., 1987). There was little variation in the rostrocaudal extent of the ICX (range, 2800-3400 $\mu \mathrm{m}$ ) across owls, and there were no significant differences in the size of the ICX between different experimental groups. The total length of axons in each zone was determined by summing the lengths of all of the individually traced segments. The number of boutons in each zone was counted using a $40 \times$ objective.

The size and location of each injection site were determined from the section in which staining was darkest. The injection site, indicated by the region containing labeled cell bodies, was measured by a case-blind observer. The mean diameter of the injection site (in $\mu \mathrm{m} \pm \mathrm{SEM}$ ) in the horizontal plane was $138 \pm 9$ for normal juveniles, $131 \pm 8$ for normal
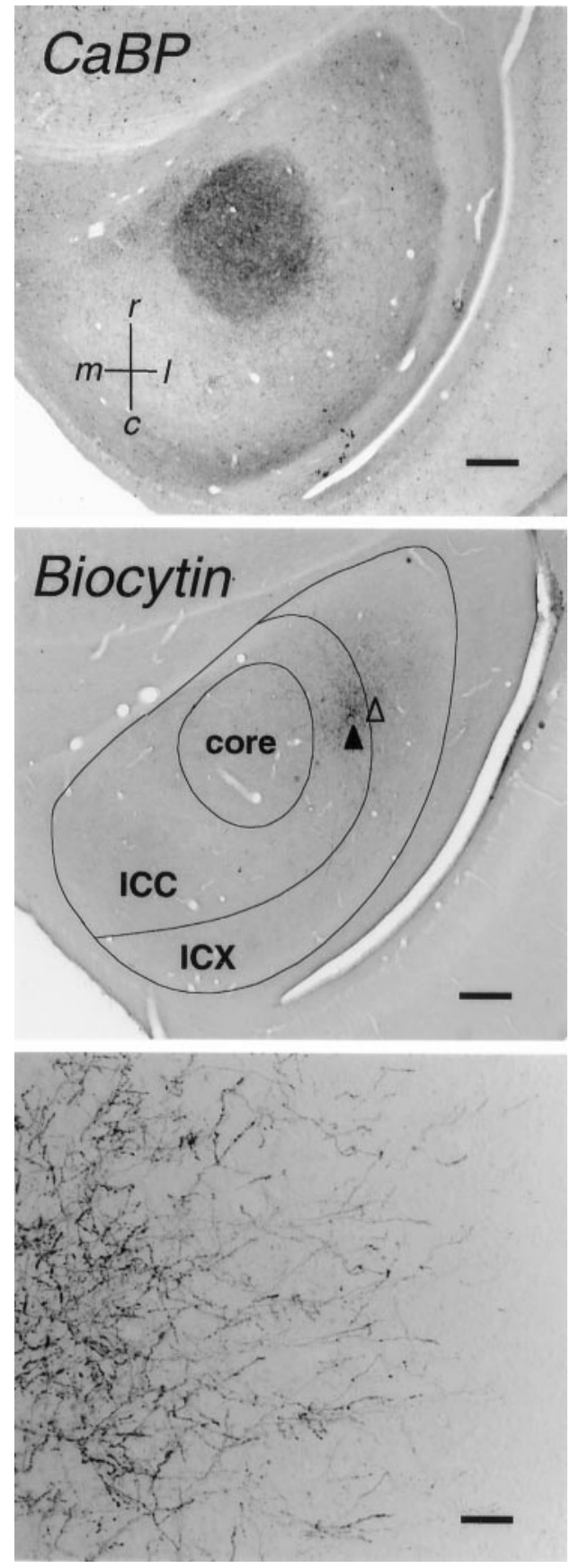

Figure 2. Visualization of the ICC-ICX axonal projection field. Top, Horizontal midbrain section reacted with an antibody to $\mathrm{CaBP}$, which stains the core subdivision of the ICC. Scale bar, $500 \mu \mathrm{m}$. Middle, Neighboring horizontal section reacted for biocytin, the anterograde tracer. Overlaid is a sketch of the CaBP section showing the relevant anatomical boundaries. The border between the ICC and the ICX was defined as $600 \mu \mathrm{m}$ from the lateral edge of the core region. At this resolution $(2 \times$ objective), the injection site is clearly visible (solid arrowhead), but the labeled ICX axons (empty arrowhead; see bottom panel) are not. Scale bar, $500 \mu \mathrm{m}$. Bottom, Labeled axons in the ICX $(10 \times$ objective). Numerous, branched, bouton-laden axons extend from the injection site into the ICX, where they terminate. For each case, the entire projection field in the ICX was traced and reconstructed. Scale bar, $100 \mu \mathrm{m}$.

adults, and $128 \pm 10$ for prism-reared adults $(141 \pm 8$ for cases with rostralward map shifts and $110 \pm 16$ for cases with caudalward map shifts; see Fig. 8 for explanation of map shifts). Although the spread of the injection site in the dorsoventral dimension was not measured, the 


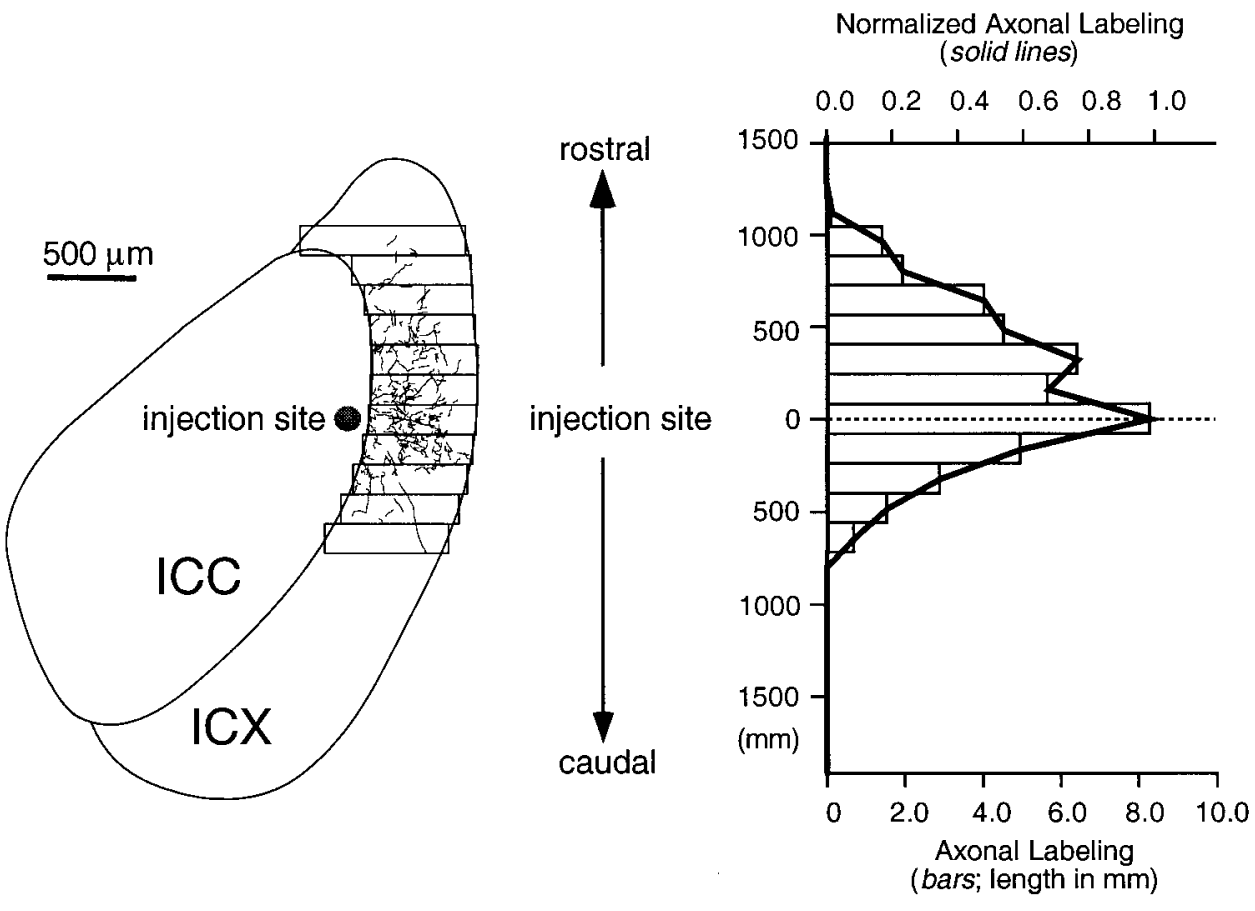

Figure 3. Quantification of the axonal projection fields. Left, Sketch of all labeled axons in the ICX from a single section containing the injection site. To quantify the length of labeled axons, the ICX was divided into zones measuring $160 \mu \mathrm{m}$ in rostral-caudal extent ( $\sim 5 \%$ of the total rostral-caudal extent of ICX) and oriented orthogonally to the rostral-caudal axis. Measurement zones are shown as rectangles. Right, Histogram of the spatial distibutions of axonal labeling. Histograms represent the total labeling across all sections for the given case. The dotted line indicates the rostral-caudal level of the injection site. The numbers along the abscissa represent the distance in micrometers from this level, measured along the rostral-caudal axis. The values along the ordinate indicate the amount of labeling contained within each measurement zone. Data are presented in two different ways. First, values in each measurement zone were normalized to the maximum value observed for the case, reflecting the spatial pattern of the projection field (i.e., top axis). Normalized axonal labeling is presented with solid lines. Second, raw values were used that reflect both the pattern and extent of the projection (i.e., bottom axis). Raw axonal labeling is presented with bars.

injection site was always contained within three or four of the $40 \mu \mathrm{m}$ sections, a maximum dorsoventral spread of $160 \mu \mathrm{m}$. An approximation of the volume of each injection site was computed from the mean diameter $(d)$ by the formula: volume $=4 / 3 * \pi *(d / 2)^{2}$. The mean computed volume of the injection site (in millions of $\mu \mathrm{m}^{3} \pm$ SEM) was $1.49 \pm 0.74$ for normal juveniles, $1.22 \pm 0.40$ for normal adults, $1.51 \pm$ 0.47 for cases with rostralward map shifts, and $0.78 \pm 0.55$ for cases with caudalward map shifts. There were no statistical differences in either mean diameter or computed volume of injection sites between any of these groups. In all cases analyzed, the injections sites were located within the lateral portion of ICC, at a mean rostrocaudal level that was $35 \%$ of the extent of the ICX (rostral $=0 \%$, caudal $=100 \%$ ), very close to the previously measured rostrocaudal level $(36 \%)$ of the representation of c20 $\mu \mathrm{sec}$ (Gold and Knudsen, 2000).

Histograms of axonal and bouton labeling were aligned relative to the rostrocaudal level of the injection site (Fig. 3). Axonal labeling was usually contained within five to eight sections (320 $\mu \mathrm{m}$ total dorsoventral extent), and the results from all sections were aligned and summed. Histograms represent either raw data or data normalized to the maximum value (for explanation, see Fig. 3 legend). Statistical analyses and graphing were accomplished using IGOR software running on a Mac G3 computer.

\section{RESULTS}

The goal of these experiments was to determine whether remodeling of the ICC-ICX projection occurs during normal development and in response to prism experience. To do this, we analyzed the spatial pattern of the ICC-ICX projection field in three groups of owls: normal juveniles, normal adults, and prism-reared adults exhibiting fully shifted ITD maps.

\section{General observations}

Figure 2 shows an example of axonal labeling in the ICX that resulted from an injection of biocytin in the ICC. In all cases, the majority of labeled processes extended laterally from the injection site, toward and into the ICX. Within the ICX, most of the processes were branched, terminated, and laden with boutons. Because no labeled cell bodies were observed in the ICX, and no label was observed in the OT, as would have occurred if the injections had encroached on the ICX (Knudsen and Knudsen,
1983; Hyde and Knudsen, 2000), we concluded that the labeling in the ICX represents the terminal fields of axonal projections from the ICC to the ICX.

Because the ICC-ICX projection is point to point, the density and location of the labeled projection field in the ICX depend on the number and location of projecting neurons in the ICC that take up biocytin, which in turn depends on the size and location of the injection site. Therefore, we restricted our analysis to those cases in which the injection sites met certain criteria (see Materials and Methods). There were no statistical differences between injection site sizes or locations between any of the experimental groups ( $t$ test, $p>0.05)$.

\section{Normal juveniles}

ICC-ICX projection fields were examined in five juvenile owls that were $\sim 60 \mathrm{~d}$ old, the earliest age at which prisms were mounted. These data indicate, therefore, the initial state of the projection field before experimentally induced adaptive plasticity.

A digital sketch of labeled axons in the ICX of a representative normal juvenile is shown in Figure 4, left panel, and the normalized projection patterns for each juvenile case $(n=7)$ are shown in the right panel. In every case, the peak density of axonal labeling occurred at the same rostrocaudal level as the site of the injection, and the mean weighted average (WA) of the distribution of labeled axons was located near this level, $70 \mu \mathrm{m} \pm 36$ caudal to the site of injection. Thus, both the peak and geometric center of the projection field were located near the rostrocaudal level of the somata of the projecting neurons, as expected from the functional maps of ITD in the ICC and the ICX (Brainard and Knudsen, 1993; Gold and Knudsen, 2000). We refer to this region in the ICX as the peak of the normal projection for ICC neurons representing $\sim \mathrm{c} 20 \mu \mathrm{sec}$.

The decline of labeled axons away from the peak appeared to be equivalent on the rostral and caudal flanks of the projection 


\section{Normal Juveniles}
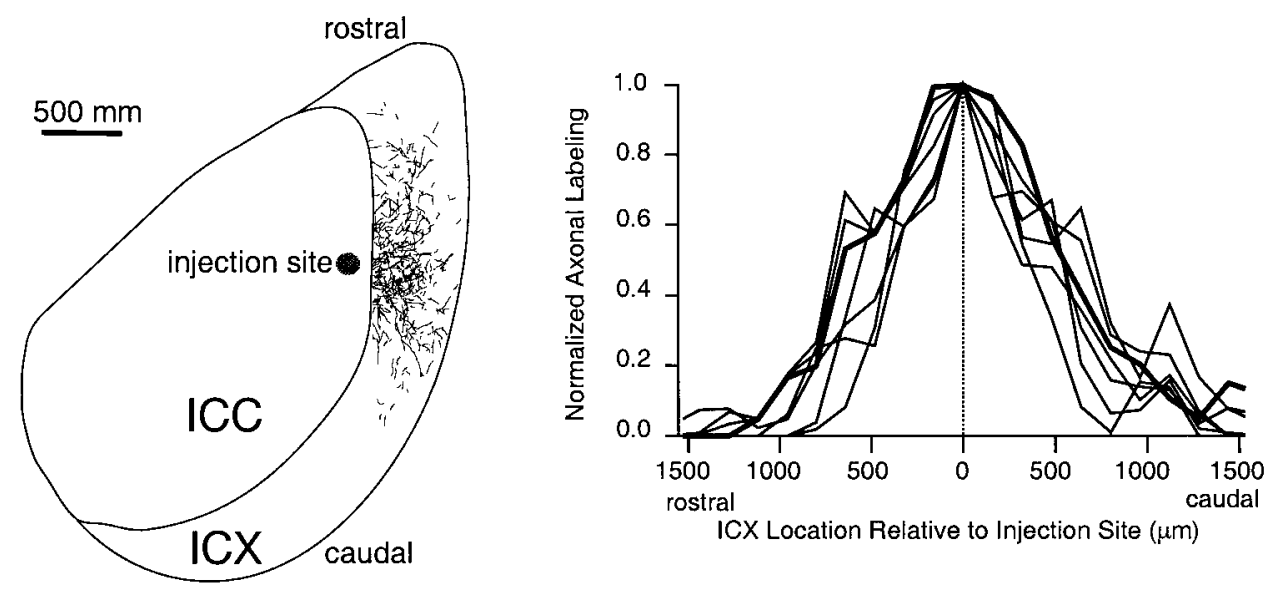

Figure 4. The ICC-ICX projection field in normal juveniles. Left, Sketch of labeled axons from the ICX in a single section containing the injection site in a representative, normal juvenile owl. Right, Spatial pattern of projection in all seven juvenile cases. The case shown on the left is indicated in bold. These data represent the total labeling across all sections for any given case, and therefore the bold trace does not match exactly the sketch shown on the left. In all cases, the projection field was spatially restricted, centered near the rostral-caudal level of the injection site, and symmetrical.

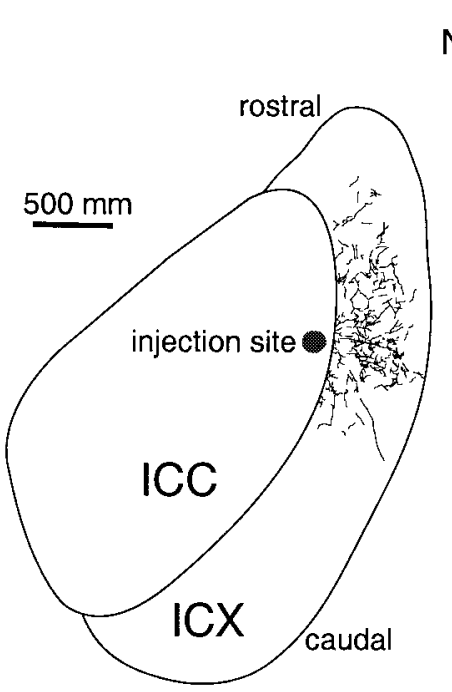

Normal Adults

Figure 5. The ICC-ICX projection field in normal adults. Left, Sketch of labeled axons from the ICX in a single section containing the injection site in a representative normal adult owl. Right, Spatial pattern of the projection in all five adult cases. The case shown on the left is indicated in bold. These data represent the total labeling across all sections for any given case, and therefore the bold trace does not match exactly the sketch shown on the left. In all cases, the projection field was spatially restricted, centered near the rostralcaudal level of the injection site, and asymmetrical with a rostral skew.

field. We used an ANOVA test to determine whether there was a significant trend toward greater labeling on one flank than on the other, by comparing the values $(n=7)$ within each measurement zone on one flank with the values from the corresponding zone on the other flank. There was no difference between the flanks (rostral flank 12\% less than caudal flank; ANOVA, $p=0.2299$ ), indicating that the projection field in juveniles was symmetrical.

\section{Normal adults}

ICC-ICX projection fields were examined in five normal adult owls. A digital sketch of labeled axons in the ICX of a representative normal adult is shown in Figure 5, left panel, and the normalized projection patterns for each adult case $(n=5)$ are shown in the right panel. In every case, the peak density of axonal labeling occurred at the same rostrocaudal level as the injection site, and the mean WA was located near this level, $107 \pm 34 \mu \mathrm{m}$ rostral to the injection site. Thus, as was true for juveniles, both the peak and geometric center of the projection field in normal adults were located near the rostral-caudal level of the somata of the projecting neurons. Unlike in juvenile owls, however, the projection field in normal adults was asymmetrical (Figs. 5, 6). On average, the amount of axonal labeling on the rostral flank was $70 \%$ greater than that on the caudal flank (ANOVA, $p<0.0001$ ).

\section{Comparison of normal juveniles with normal adults}

To investigate whether axonal remodeling occurs during normal development, we compared the juvenile and adult composite projection patterns (Fig. 6A). The width of the projection, quantified as the rostrocaudal extent of axonal labeling at half of the maximum axonal density, was $31 \%$ narrower in adults (mean width $733 \pm 66 \mu \mathrm{m}$ SEM) than in juveniles (mean width $1065 \pm$ $92 \mu \mathrm{m} \mathrm{SEM})$. The difference between these values was statistically significant ( $t$ test, $p=0.0232$ ) and indicates that the ICCICX axonal projection sharpens during normal development after $60 \mathrm{~d}$ of age.

The sharpening of the juvenile projection field could have resulted from either a net elaboration of axons at the peak of the normal projection or from a net elimination of axons on the flanks of the field. To distinguish between these possibilities, we compared total axonal labeling between juvenile and adults owls.

Composite curves of the spatial distribution of axonal labeling were constructed from unnormalized data, reflecting not only the pattern, but also the absolute magnitude of axonal labeling. The composite distributions for juvenile and adult owls are shown in Figure $6 B$. The data suggest a net elimination of axons during normal development. However, the difference in total axonal labeling across the entire projection $(35,942 \pm 2,365 \mu \mathrm{m}$ for 


\section{Normal Juveniles (black) vs. Normal Adults (grey)}

A

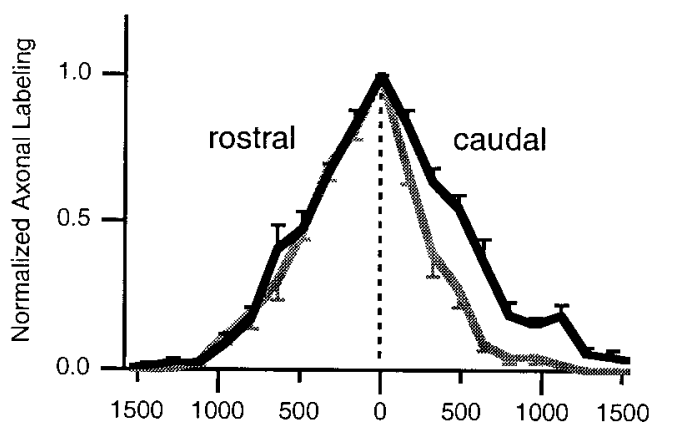

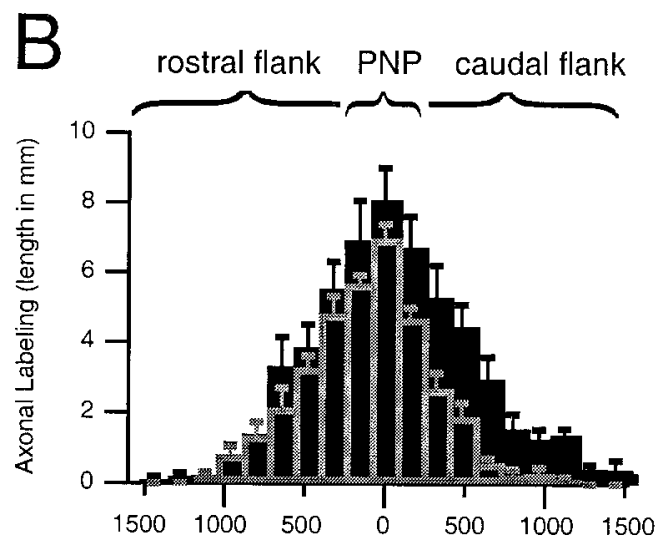

ICX Location Relative to Injection Site ( $\mu \mathrm{m})$

Figure 6. Comparison of normal juvenile with normal adult axonal projection fields. $A$, Composite spatial pattern for normal juveniles (black line) and normal adults (gray line). These were obtained by averaging the individual cases shown in Figures 4 and 5, respectively. The error bars (SEM) reflect case-to-case variation. $B$, Composite spatial distributions of total axonal labeling. These histograms reflect both the spatial pattern and the extent of the projection fields. The different subregions of the projection fields are indicated by brackets above the data. The peak of the normal projection (PNP) was defined as the measurement zone that contained the greatest amount of axonal labeling and the measurement zones on either side. The rostral and caudal flanks were defined as all locations rostral to and caudal to, respectively, the PNP. Direct inspection reveals that during normal development, there is a net elimination of axons predominantly from the caudal flank of the projection field.

adults, $55,810 \pm 8,242 \mu \mathrm{m}$ for juveniles) was not statistically significant $(t$ test, $p=0.0771)$.

To test whether axonal elimination occurs within specific regions of the projection field, we divided the field into three subregions and examined the average amount of axonal labeling in each. These subregions were the peak of the normal projection (PNP), the rostral flank and the caudal flank, as indicated in Figure $6 B$. The PNP was defined as the measurement zone that contained the highest density of axonal labeling, plus the adjacent zone on each side. The total length of axons in the PNP was $20 \%$ lower in adults than in juveniles (ANOVA, $p=0.0482$ ). Thus, there was evidence of a small, net axonal elimination at the peak of the normal projection after the owls were $60 \mathrm{~d}$ old. There was no significant reduction in axonal labeling along the rostral flank of the projection field (18\% decrease from juvenile to adult; ANOVA, $p=0.1349)$. In contrast, axonal labeling along the caudal flank was $68 \%$ lower in adults than in juveniles (ANOVA, $p<0.0001)$. It is very unlikely that the small, nonsignificant differences in injection site size between adults and juveniles (5\% smaller mean diameter, $18 \%$ smaller mean computed volume) could alone explain such a large difference in labeling on the caudal flank, even more so given the differential effect on the caudal flank when compared with either the rostral flank or PNP. Thus, taken together, these results indicate that there was a net elimination of axons from the caudal flank of the projection field during normal development after $60 \mathrm{~d}$ of age (see Fig. 14).

We next asked whether the distribution of synaptic boutons within the projection field changed during normal development. The spatial distribution of boutons was assessed by counting the number of boutons in each measurement zone (Fig. 7A). To obtain bouton frequency plots for each case, the spatial distribution of bouton number was divided by the spatial distribution for total axonal length. In all juvenile and adult cases (Fig. 7B), bouton frequency was constant at approximately nine boutons per $100 \mu \mathrm{m}$ of axon across the entire projection field. Comparison of bouton frequency within or between subregions of either group revealed no statistical differences $(t$ test, $p>0.05)$. Thus, there was no net change in bouton frequency after $60 \mathrm{~d}$ of age.

In summary, the results from the normal owls indicated that refinement of the ICC-ICX axonal projection occurred after $60 \mathrm{~d}$ of age, resulting predominantly from commensurate losses of axons and boutons from the caudal flank of the projection field.

\section{Prism-reared owls}

ICC-ICX projection fields were examined in seven prism-reared owls. Four of these owls had prisms attached at $\sim 60 \mathrm{~d}$, and three had prisms attached at $\sim 100 \mathrm{~d}$. All but one, case MnL, exhibited large-scale shifts in ITD tuning as measured in the OT before the injection of biocytin (Table 1). Case MnL will be discussed later.

Adjustment to prisms involves a shift of the ITD maps on both sides of the brain. Because each ICX contains a map of contralateral space, prism experience causes a rostralward shift of the ITD map on one side of the brain and a caudalward shift on the other, as illustrated in Figure $8 A$. Therefore, if anatomical remodeling underlies these map shifts, ICC-ICX projection fields should be skewed rostralward on one side and caudalward on the other, with the direction of shift depending on the direction of prismatic displacement. Consequently, the prism-reared cases were sorted into two groups: those that exhibited, physiologically, rostralward shifts of the map and those that exhibited caudalward shifts.

Digital sketches of labeled axons in the ICX of representative cases with rostralward and caudalward map shifts are shown in Figure $8 B$. As predicted by the axonal remodeling hypothesis, these projection fields are abnormal and are skewed rostralward and caudalward, respectively, in the adaptive direction. Similar results were observed in all prism-reared owls with physiological map shifts (Fig. 9).

In all four cases with rostralward map shifts, the peak density of axonal labeling occurred rostral to the level of the injection site (Fig. 9). These results differ from those observed in all 12 normal owl cases, in which the highest density of axonal labeling occurred at the same rostrocaudal level as the injection site. In addition, the 

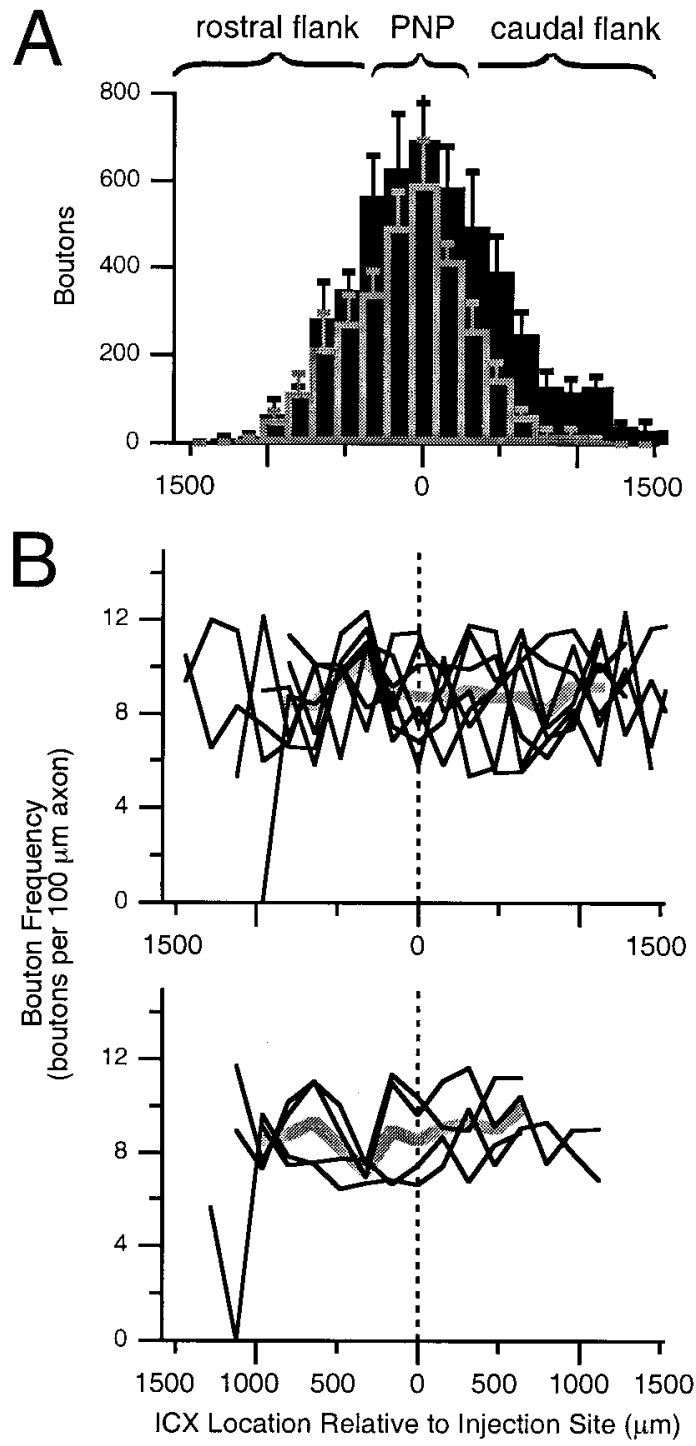

Figure 7. Spatial distributions of boutons and bouton frequency in normal juvenile and normal adult owls. $A$, Composite spatial distributions of boutons for normal juveniles (black bars) and normal adults (gray bars). These were obtained in an analogous manner as those for axonal labeling (Fig. 6). The error bars indicate SEM. B, Bouton frequency plots for all juvenile (top) and four of the five adult cases (bottom). Boutons were not counted in the one adult case in which BDA was used as the anterograde tracer. Bouton frequency was defined as the number of boutons per 100 $\mu \mathrm{m}$ axon. The bold gray trace indicates the average of the individual cases. There were no statistical differences between any two subregions in either group.

WAs from the cases with rostralward map shifts were all skewed rostrally $($ mean $=246 \pm 54 \mu \mathrm{m}$ rostral), although the magnitude of the changes was not significant ( $t$ test, $p=0.0570)$. In two of the three caudalward cases, the highest density of axonal labeling occurred caudal to the level of the injection site; in the remaining case, $\mathrm{PhL}$, a substantial second peak in the projection pattern was observed at an abnormally caudal location (Fig. 9). In addition, all of the WAs of the caudalward cases were skewed caudally (mean $=195 \pm 72 \mu \mathrm{m}$ caudal) and were significantly different from those measured in normal adults ( $t$ test, $p=0.0049)$. Thus, prism rearing caused both the peak (rostralward and caudalward cases) and geometric center (caudalward cases) of the ICC-ICX projection field to be displaced in the adaptive direction.
We next compared the spatial distributions of absolute amounts of axonal labeling in prism-reared owls with those in normal adults. Composite curves of amounts of axonal labeling were constructed separately for rostralward and caudalward cases. These composite distributions are shown overlaid with the corresponding composite distributions for normal adults in Figure $10 A$. We compared these distributions for three subregions: the adaptive flank (i.e., rostral flank for rostralward map shifts and caudal flank for caudalward map shifts), the PNP, and the nonadaptive flank (i.e., caudal flank for rostralward map shifts and rostral flank for caudalward map shifts).

In both rostralward and caudalward cases, the amount of axonal labeling on the adaptive flank was dramatically greater, 4.1and 3.7-fold, respectively, than on the corresponding flank for normal adults. In contrast, the amount of axonal labeling at the PNP was only slightly greater, by 1.68 - and 1.23-fold, respectively. The amount of axonal labeling on the nonadaptive flank was lower in caudalward cases (0.66-fold of the normal adult) but, surprisingly, higher in rostralward cases (2.77-fold of the normal adult). Thus, relative to the projection field in normal adults, prism-rearing resulted in a large net increase of axons in the adaptive portion of the field and smaller changes in the amount of axons in the nonadaptive portion of the field (see Fig. 15).

Because refinement of the ICC-ICX projection during normal development involved axon elimination, the prism-induced increases in axonal labeling in adults could have been caused either by a failure of axon elimination or by axon elaboration. To test whether axon elaboration had indeed occurred, we compared the composite distributions of axonal labeling for prism-reared owls with those of normal juveniles (Fig. 10B).

Axonal labeling on the adaptive flank in rostralward cases was dramatically larger, by 2.3 -fold, in prism-reared versus normal juvenile owls (ANOVA, $p<0.0001$ ), indicating a net elaboration of axons on the adaptive flank of the projection field. In contrast, there was no evidence of axon elaboration on the adaptive flank in caudalward cases. In these cases, the amount of axonal labeling on the adaptive flank was not significantly different from that in juvenile cases (1.17-fold higher; ANOVA, $p=0.2692$ ).

Axonal labeling on the nonadaptive flank in rostralward cases was indistinguishable from that in juveniles (0.88-fold; ANOVA, $p=0.3590)$, indicating that there was no net elimination of nonadaptive axons in these cases. In contrast, the amount of axons on the nonadaptive flank of caudalward cases was lower than in juveniles (0.54-fold; ANOVA, $p=0.0085)$, indicating a net elimination. In no case was a net elaboration of nonadaptive axons observed.

The total amount of axonal labeling at the PNP was slightly higher, by 1.35 -fold, in rostralward cases than in normal juveniles (ANOVA, $p=0.0360$ ) and was unchanged in caudalward cases (0.98-fold; ANOVA, 0.8953). This result suggests that once the projection to the PNP is established by $60 \mathrm{~d}$ old, prism experience caused only modest changes in the net balance of axon elaboration and elimination at the PNP (see Fig. 15).

The persistence of axons at the peak of the normal projection field in prism-reared owls was not reflected in the physiological responses recorded in the ICX: responses to normal ITD values were dramatically weaker than responses to adaptive ITD values. One possible explanation for this discrepancy is that synapses were selectively eliminated from the normally targeted axons. As an initial test of this hypothesis, we asked whether the spatial distribution of synaptic boutons was altered as a result of prism experience. 
A
Caudalward Map Shift

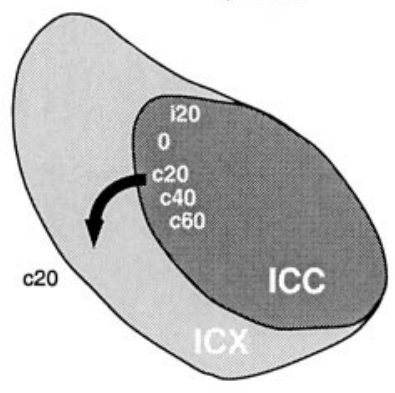

\section{Rostralward Map Shift}

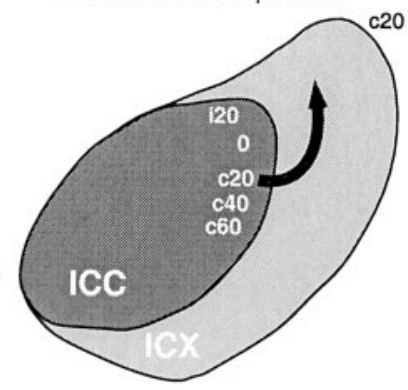

B

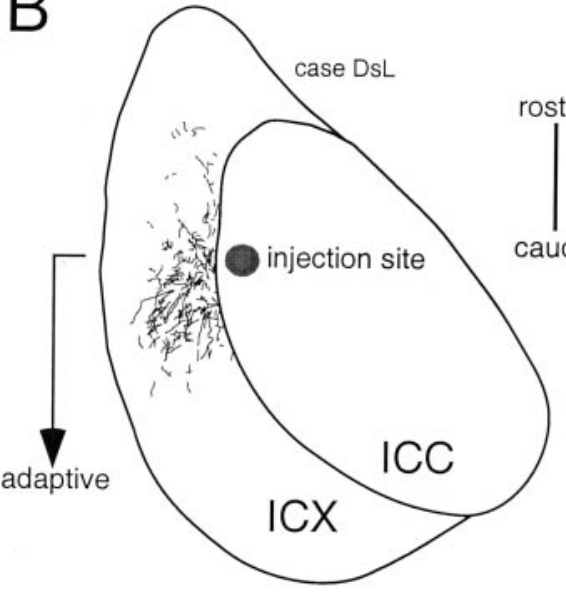

Rostralward Map Shifts
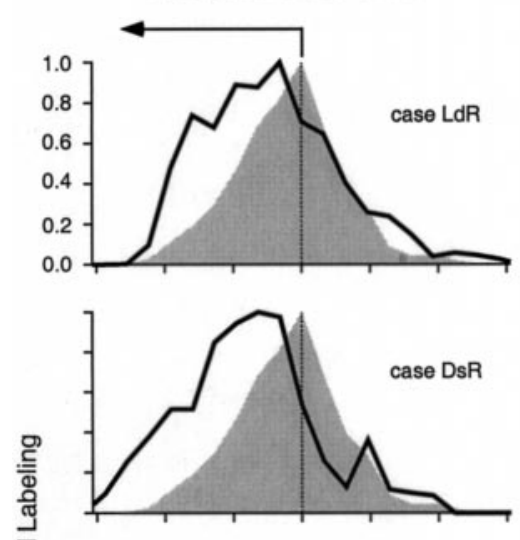

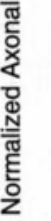
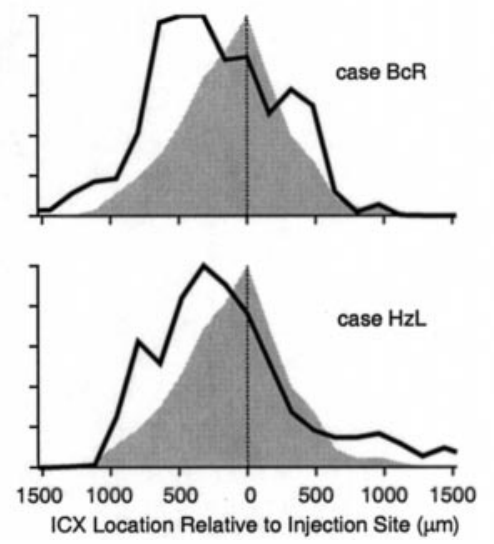

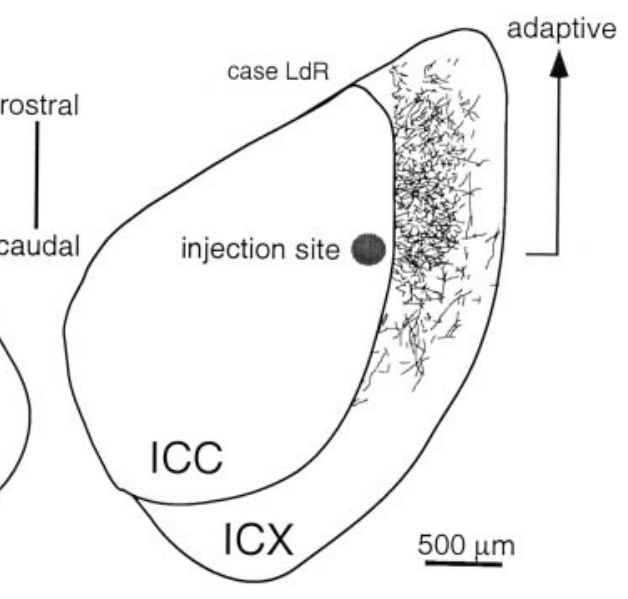

Figure 8. A, The axonal remodeling hypothesis. The static representation of ITD in the ICC is indicated in microseconds. Experience with right-shifting prisms causes the acquisition of responses to more left-earleading ITDs in the ICX on both sides of the brain. On the left side, left-ear-leading ITDs are represented rostrally in the ICC, and therefore the hypothesis predicts a caudal skew of the ICC-ICX axonal projection pattern. On the right side, left-ear-leading ITDs are represented caudally, and the hypothesis predicts a rostral skew. $B$, Sketches of labeled axons in the ICX from single sections containing the injection site for a caudalward map shift (left panel) and a rostralward map shift (right panel). Map shifts were measured physiologically. In both cases, there was an expansion, compared with normal adults, of axonal labeling in the adaptive direction.
Figure 9. ICC-ICX projection fields in prism-reared owls (thick black lines). The normal adult composite pattern is shown in gray for comparison. In all four cases with a rostralward map shift, the projection pattern is skewed rostrally, and in all three cases with a caudalward map shift, the projection is skewed caudally. 
Visual inspection of the biocytin-labeled material revealed no qualitative difference between boutons and axons in different subregions of the projection fields. Representative high-magnification images of axons in these subregions from a prism-reared owl are shown in Figure 11. At both locations, bouton-laden axons, branched axons, axon terminals, and terminal boutons were observed. Thus, at this level of scrutiny, the normally targeted axons were indistinguishable from the newly elaborated ones.

Composite bouton distributions for rostralward and caudalward cases are shown in Figure $12 A$, overlaid with the comparable composites for juveniles. Comparisons of bouton frequency (Fig. 12B) between the PNP, adaptive, and nonadaptive subregions in prism-reared owls revealed no significant differences $(t$ test, $p>0.05)$.

We examined bouton frequency on individual axonal segments that were at least $100 \mu \mathrm{m}$ in length. These measurements were made on the rostral flanks from four normal juveniles and four prism-reared owls (rostral cases only). As shown in Figure 13, the distributions of bouton frequencies were similar. Therefore, the increase in bouton number on the rostral flank of cases with rostralward map shifts cannot be explained by a high density of boutons on a subset of preexisting axons.

In summary, for rostralward map shifts, prism-induced axonal remodeling involved commensurate increases in the amount (relative to juveniles) of axons and boutons on the adaptive flank and little change in the amounts of axons and boutons at either the normal peak of the projection field or on the nonadaptive flank. These changes can be appreciated in the side-by-side comparison of representative cases shown in Figure 15. For caudalward shifts of the map, remodeling could be accounted for by prevention of normally occurring elimination of axons and boutons on the caudal flank and by a net elimination of axons and boutons on the rostral flank (Fig. 15).

\section{Case MnL}

One owl, case MnL, was $120 \mathrm{~d}$ old and had worn prisms for only $17 \mathrm{~d}$ at the time of injection. This short duration of prism experience did not lead to a shift in the ITD maps, as indicated by normal ITD tuning measured in the OT on the day of biocytin injection (best ITD shift $=0.7 \mu \mathrm{sec}$ ). The axonal projection pattern in case ML (Fig. 14) was indistinguishable from those in normal adults in terms of target location, width, flank asymmetry, and total amount of axonal labeling. Thus, at this early stage in the adjustment process, adaptive axonal remodeling was not evident.

\section{DISCUSSION}

Our results demonstrate that experience-dependent plasticity in the barn owl auditory space map involves topographically appropriate axon elaboration and synaptogenesis. This growth represents the formation of an adaptive neuronal circuit. Thus, the anatomical model for experience-dependent plasticity first proposed by Feldman and Knudsen (1997) has been confirmed. In addition, we have shown that topographically restricted elimination of axons and boutons occurs during the normal development of the map.

\section{Axonal remodeling during normal development}

In normal juveniles, the ICC-ICX projection field is spatially restricted, symmetrical, and centered at the rostrocaudal level of the somata of the projecting neurons (for neurons representing c20 $\mu \mathrm{sec})$. The projection field in adult owls is similarly centered but is $\sim 30 \%$ narrower, indicating that refinement occurs during normal development. This refinement involves a net elimination of axons and boutons from, predominantly, the caudal flank of the juvenile projection field (Figs. 6, 15).

As a result of selective sculpting, the adult projection field is asymmetrical relative to its peak density. Yet a physiological correlate of these projection fields, the shapes of the ITD tuning curves recorded in the ICX, are symmetrical relative to the most effective ITD (Brainard and Knudsen, 1993). Therefore, the asymmetry of the projection should result in a compression of the representation of contralateral-ear-leading ITDs. Indeed, in the ICX, less territory is devoted to ITDs representing contralateral space (located caudally) than to frontal space (located rostrally) (Fig. 1).

\section{Axonal remodeling during adaptive plasticity}

The ICC-ICX projection field in prism-reared owls is dramatically different from that in normal owls (Figs. 8-10, 12, 15, Table 2). The predominant effect is an increase in the density of boutonladen axons within the subregion of the ICC-ICX projection field that corresponds to the direction of prismatic displacement of the visual field (i.e., the adaptive flank). These axons and synapses are appropriately located to convey activity to support adaptive responses in the ICX.

Does remodeling of the adaptive flank occur by selective elaboration of axons and boutons or by selective prevention from elimination? Our results show that both mechanisms may be involved. For rostralward shifts, anatomical elaboration must be involved: the axonal density and number of boutons on the adaptive (rostral) flank in prism-reared adults is 2.3 -fold greater than on the rostral flank in juveniles. In contrast, no net axonal elaboration was observed for caudalward shifts. Remodeling of the adaptive flank in these cases can be accounted for by either a prevention of the normal axon elimination or by compensatory axon elaboration. Caudal axons and synapses, which are normally eliminated during development because they convey inappropriate ITD information, may instead be maintained in prism-reared owls because they convey adaptive ITD information for a caudalward shift of the map (Fig. 16).

Where elaboration is evident, the vast majority of it is located within the range of the juvenile projection field. Therefore, axon elaboration could occur predominantly by local sprouting (Fig. 16). Whether long-distance extension of axons can take place in this pathway cannot be concluded from this study, because the prismatic displacement corresponded to a physiological shift that was within the range of the juvenile projection.

\section{Evidence for synaptogenesis}

The dramatic increase in the number of boutons on the adaptive flank in prism-reared owls with rostralward map shifts could reflect either an increase in the number boutons on preexisting axons or the genesis of boutons on newly elaborated axons. These possibilities can be distinguished by comparing the probability distributions of bouton frequencies on the adaptive flank between juvenile and prism-reared owls (rostralward cases only). The distribution for juvenile owls is unimodal. If, in prism-reared owls, all new boutons occurred on preexisting axons, the distribution for these owls would be bimodal, with one peak at zero, corresponding to newly added, boutonless axons, and the remainder of the distribution shifted toward higher bouton frequencies (relative to juveniles), corresponding to overcrowding of boutons on preexisting axons. As shown in Figure 13, no boutonless axon 

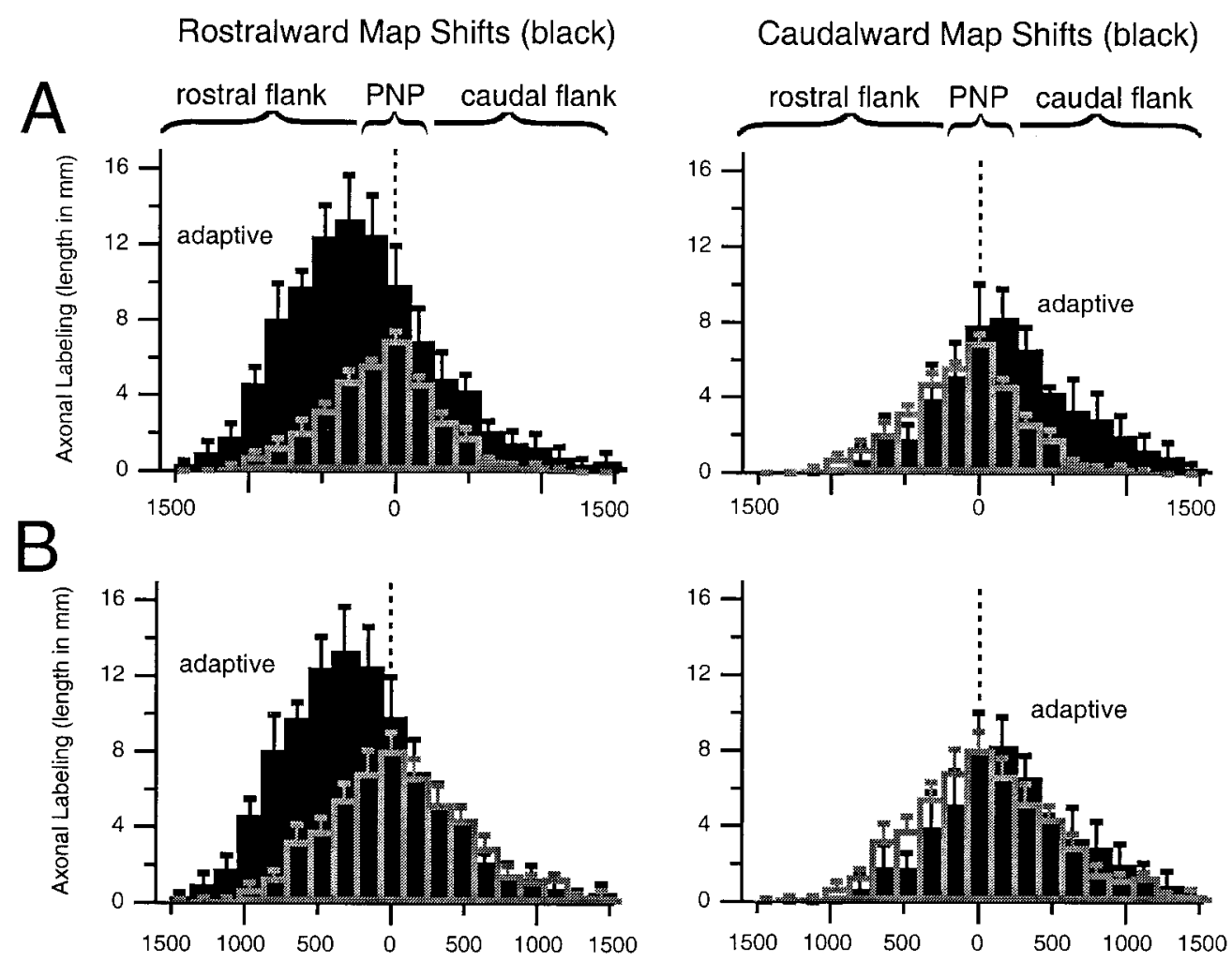

Figure 10. Spatial distributions of total axonal labeling in prism-reared owls (black bars) and normal owls (gray bars). The error bars indicate SEM. $A$, Rostralward (left) and caudalward (right) map shifts versus normal adults. $B$, Rostralward (left) and caudalward (right) map shifts versus normal juveniles. All ICX Location Relative to Injection Site $(\mu \mathrm{m})$ axes and labels are as in Figure $6 B$

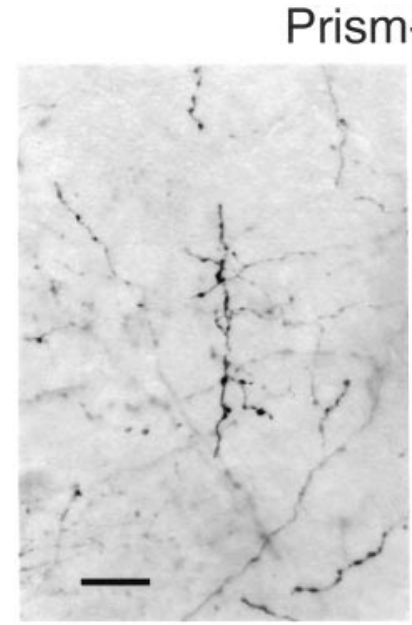

PNP

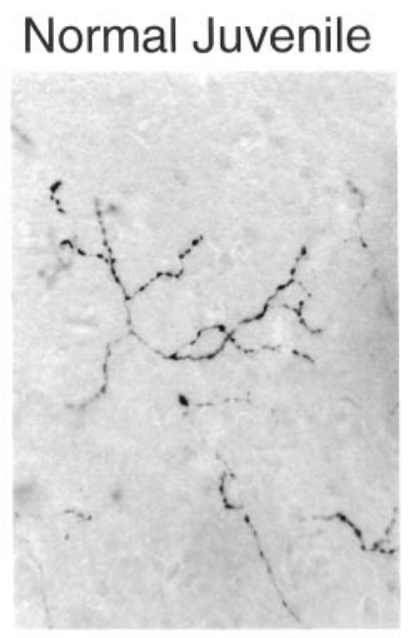

rostral flank
Figure 11. Bouton-laden axons in the ICX (40× objective). Representative axons located at the peak of the normal projection in a prism-reared owl with a rostralward map shift (left panel), the rostral flank in the same owl (middle panel), and the rostral flank of a normal juvenile (right panel). Scale bar, $20 \mu \mathrm{m}$. segments were observed in the rostral zone of prism-reared owls with rostralward map shifts. Thus, the newly elaborated axons that appeared in these cases bore boutons. Previous studies have shown that nearly all (if not all) tracer-labeled boutons identifiable with the light microscope contain presynaptic structures when examined with the electron microscope (Somogyi et al., 1982) and therefore represent synapses. Thus, the appearance of boutons on newly elaborated axons demonstrates that synaptogenesis has occurred.

Because not all presynaptic structures manifest as boutons, especially during early development (LeVay and Stryker, 1979), our methods may underestimate the number of functional synapses that are induced during experience-dependent adaptive plasticity.

\section{Maintenance of the normal projection field}

In prism-reared owls, axonal labeling at the peak of the normal projection was maintained at levels comparable to or greater than those in normal juveniles and adults (Figs. 10, 15). This result has three implications.

First, there appears to be little competition, at the anatomical level, between the normal and adaptive projection fields. The sets of axons and synapses that convey the activity supporting the normal and adaptive responses coexist. The normal axons persist despite a prolonged period (usually $>1$ year) when their activity does not result in postsynaptic action potentials, indicating that synchronous postsynaptic action potential responses are not required to maintain the normal inputs. In this respect, experience- 

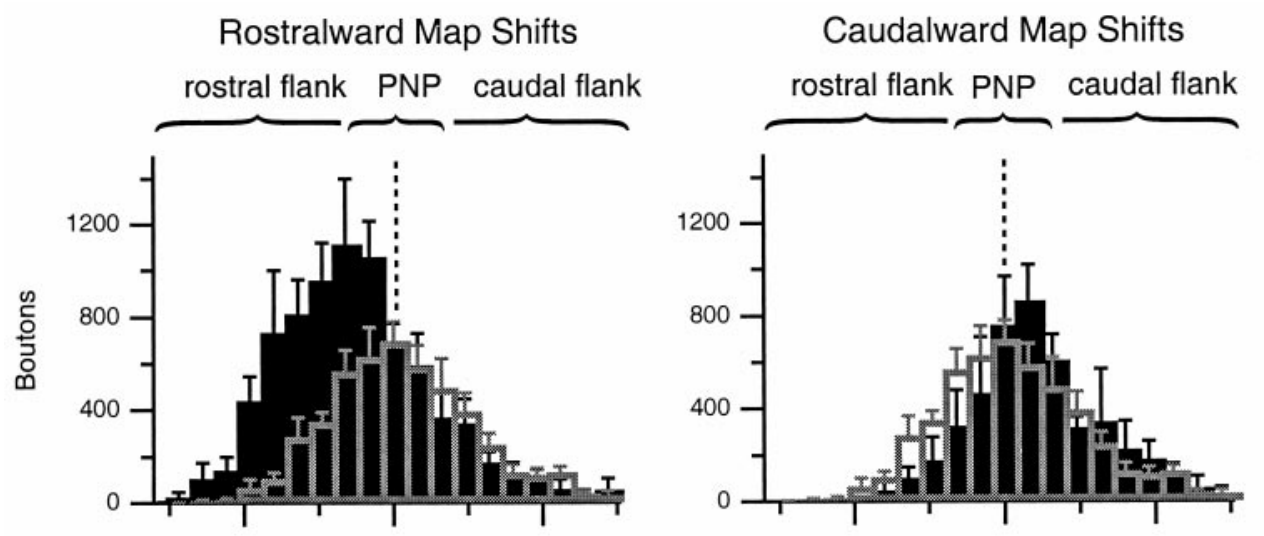

Figure 12. Top panels, Spatial distributions of boutons for prism-reared owls (black bars) and normal juveniles (gray bars). The error bars indicate SEM. Bottom panels, Bouton frequency plots for rostralward (left) and caudalward (right) map shifts. The bold gray traces indicate the averages of the individual cases.
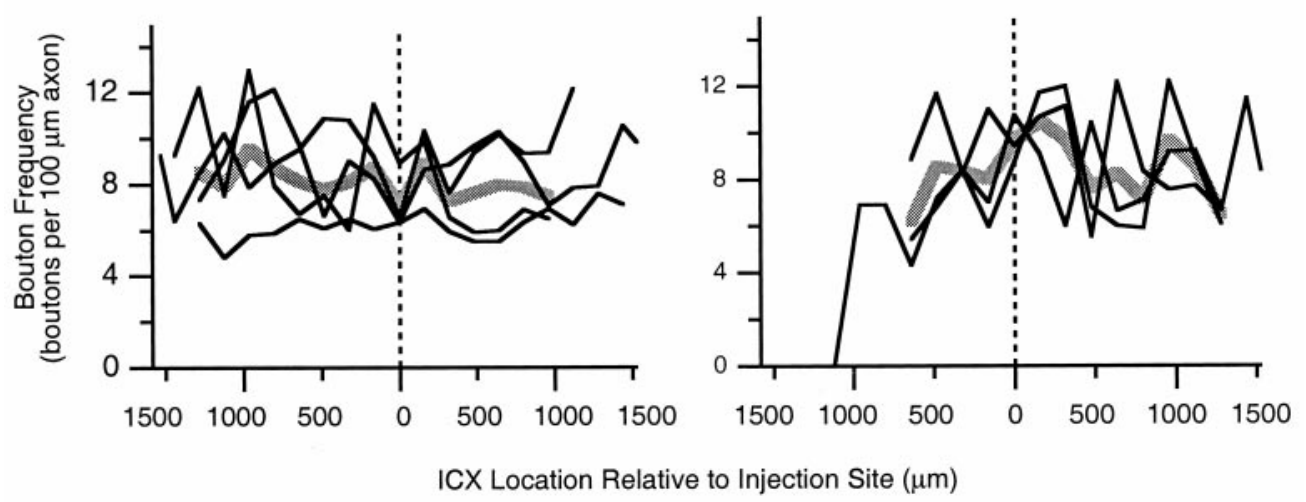

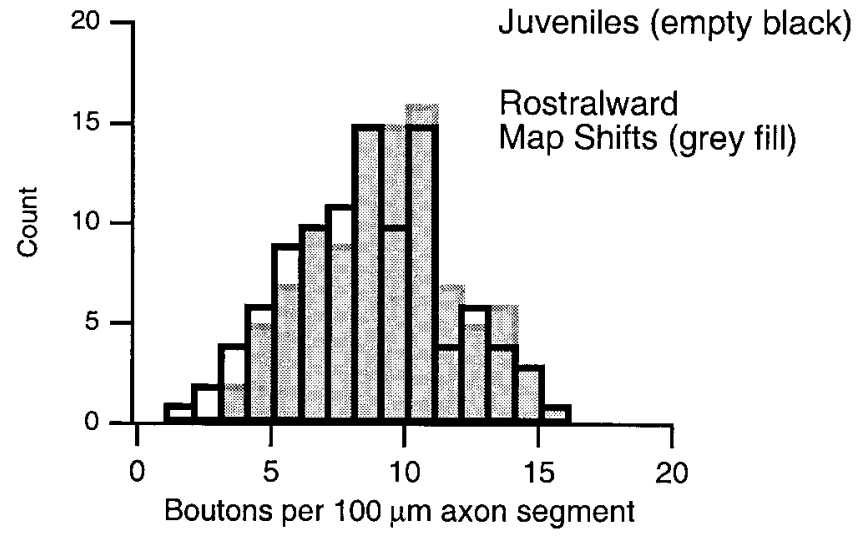

Figure 13. Probability distributions of bouton frequency. The bars indicate the number of $100-\mu \mathrm{m}$-long axonal segments with the given bouton frequency. Measurements were made on the rostral flank in normal juvenile and in prism-reared owls with rostralward map shifts. One hundred individual axon segments were examined in each group.

dependent plasticity in this system differs from that observed in mammalian systems. For instance, even brief (4 d) monocular deprivation in cats leads to shrinkage of geniculocortical afferents serving the occluded eye (Antonini and Stryker, 1993, 1996).

Second, in prism-reared owls, the persistence of the normal anatomical projection, despite the absence of its functional expression, requires that a mechanism exists to prevent postsynaptic action potential responses to the normal inputs. Previous work has shown that GABAergic inhibition plays a major role in suppressing these responses (Zheng and Knudsen, 1999).

Third, the persistence of the normal projection could provide
ICX Location Relative to Injection Site ( $\mu \mathrm{m})$

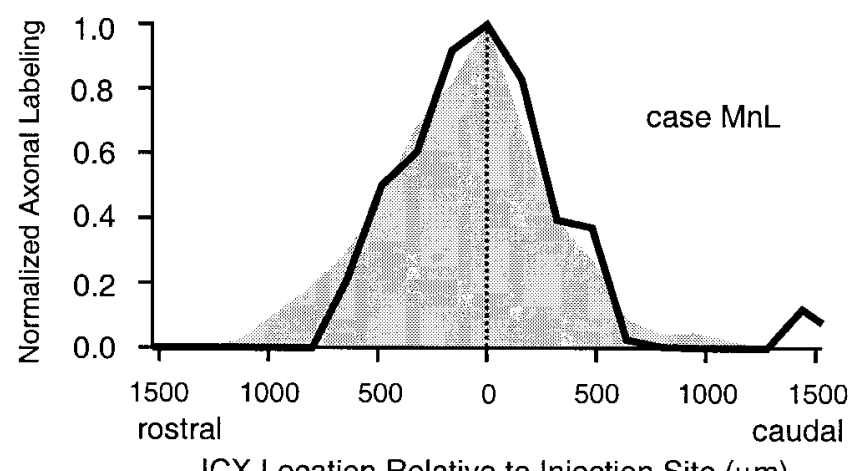

ICX Location Relative to Injection Site $(\mu \mathrm{m})$

Figure 14. ICC-ICX projection pattern in an owl with prism experience but no physiological map shift. The normal adult composite is shown in gray.

an anatomical basis to enable adults to re-express responses to normal ITDs after a period of normal experience (Knudsen, 1998). After prism removal, postsynaptic responses to the persisting normal inputs may be gradually re-expressed through a combination of synaptic strengthening and release from differential GABAergic inhibition.

\section{Comparison with other systems}

Axonal remodeling has been demonstrated in the visual system in response to monocular deprivation (Shatz and Stryker, 1978; Antonini and Stryker, 1993, 1996) or focal retinal lesions (DarianSmith and Gilbert, 1994) and in the somatosensory system in response to limb deafferentation (Florence and Kaas, 1995). The paradigm that we used is distinctive from these in several ways. First, prism-rearing does not involve deprivation or denervation. 

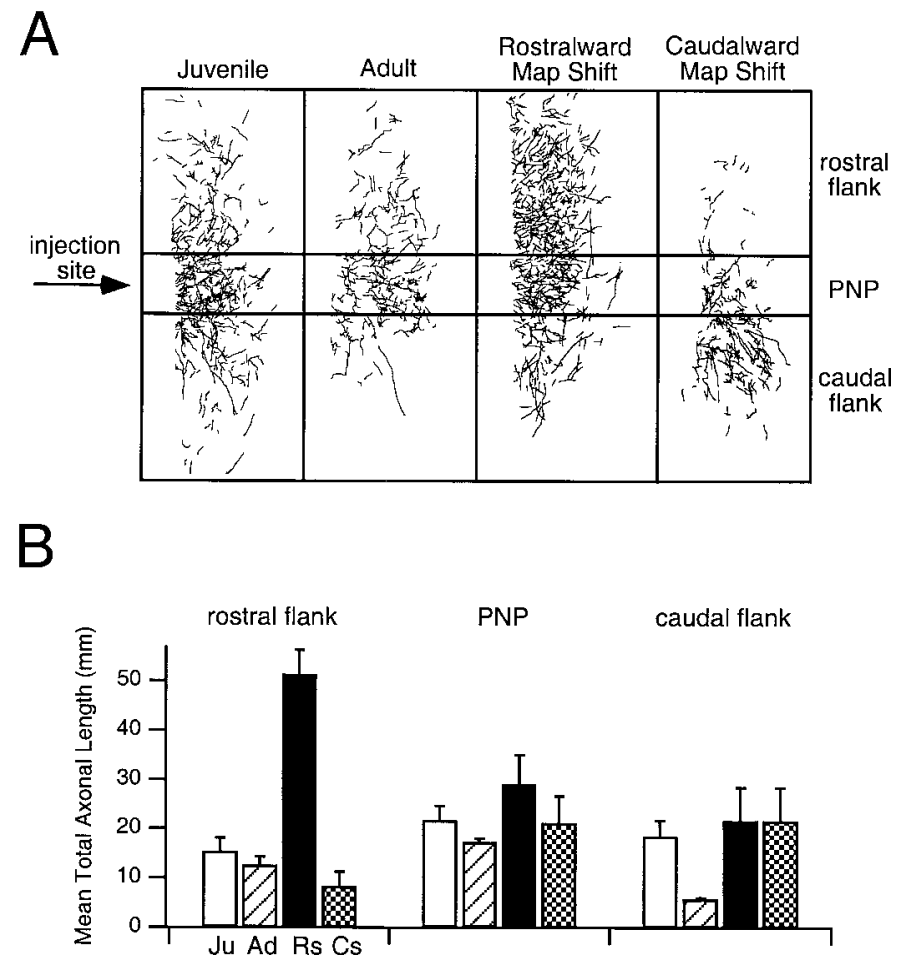

Figure 15. A, Representative axonal sketches of sections from normal juvenile, normal adult, and prism-reared owls with rostralward and caudalward map shifts. The rostrocaudal level of the injection site is indicated on the left. B, Mean total axonal labeling at each subregion of the ICC-ICX projection field in all four experimental groups: normal juveniles (open bars), normal adults (diagonal hatching), rostralward map shifts (solid black), and caudalward map shifts (checkerboard).

Such experimental treatments cause an imbalance in activity between competing afferent channels, for example (Antonini and Stryker, 1998). In contrast, prism rearing does not alter the amount or pattern of auditory-driven activity in either the ICC or ICX. Second, prism-induced auditory plasticity is not the result of self-organization but rather is the result of supervised learning driven by a visually based instructive signal (Knudsen, 1994). Third, the experiential effect of prism rearing, which chronically alters the correspondence between acoustic cue values and the locations in the visual field that produce them, resembles the natural, visually based calibration of idiosyncratic and changing auditory cues and not a pathological state. Finally, prism-induced plasticity is behaviorally adaptive, a feature that is difficult to establish in many other systems.

A close parallel to the anatomical plasticity described here is

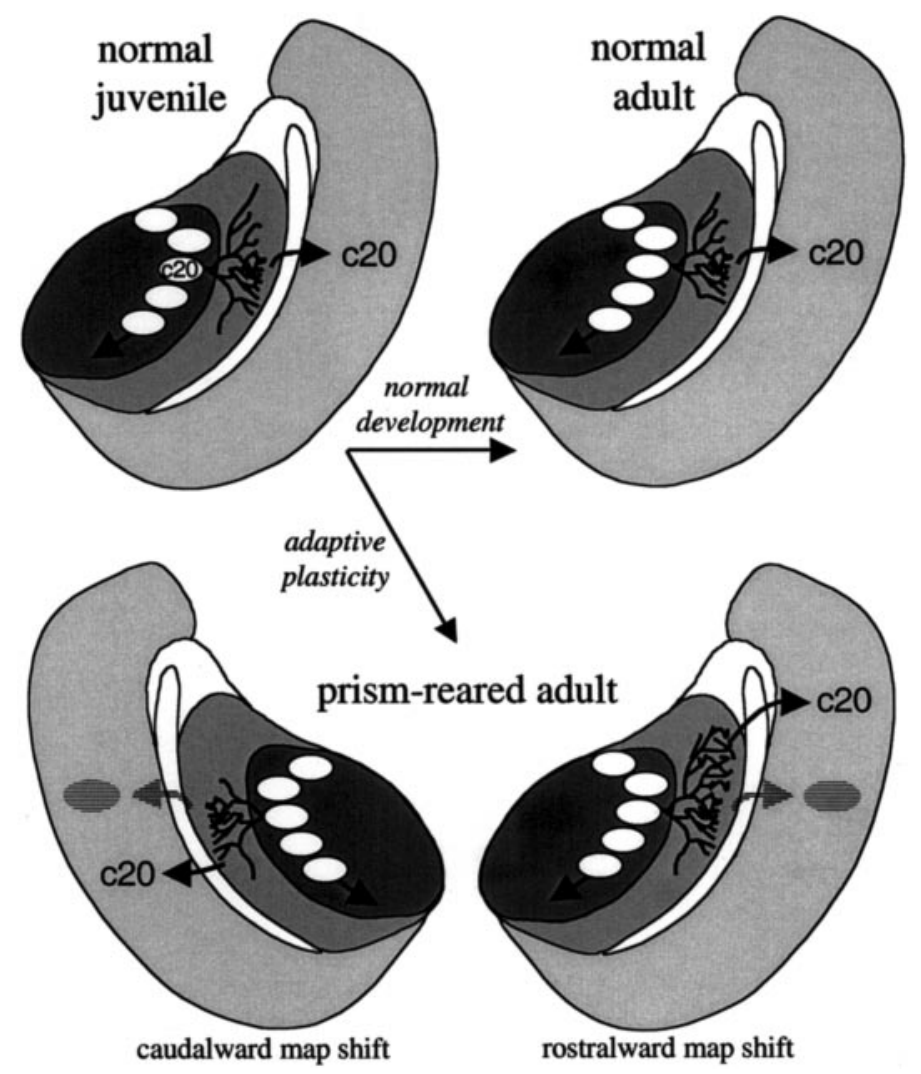

Figure 16. Schematic summary of adaptive axonal remodeling. The axons representing c20 $\mu \mathrm{sec}$ are shown in bold. The normal juvenile projection (top left), representing the initial state of the projection, is broad and symmetrical. During normal development, there is a net elimination of axons and boutons predominantly from the caudal flank of the projection, resulting in an adult projection (top right) that is narrower and asymmetrical. Prism experience alters the net balance between axon elaboration and elimination. For rostralward map shifts (bottom left), remodeling occurs by a net elaboration of axons that is largely restricted to the rostral flank of the projection. For caudalward map shifts, remodeling occurs by a net elimination of axons on the rostral flank and a net preservation of axons on the caudal flank.

found in the frog optic tectum (Udin and Keating, 1981; Guo and Udin, 2000). Binocular visual receptive fields in the frog optic tectum are established by convergence of direct inputs from the contralateral retina and indirect inputs from the ipsilateral retina, via the contralateral nucleus isthmi. Rotation of one eye in tadpoles leads to an adaptive change in the topography of the crossed, isthmotectal connections and a realignment of binocular receptive fields (Udin and Grant, 1999). In addition, and similar

\section{Table 2. ICC-ICX axonal labeling representing $\sim \mathrm{c20} \mu \mathrm{sec}$ ITD}

\begin{tabular}{|c|c|c|c|c|}
\hline & Juveniles & Adults & $\begin{array}{l}\text { Rostralward map } \\
\text { shifts }\end{array}$ & $\begin{array}{l}\text { Caudalward map } \\
\text { shifts }\end{array}$ \\
\hline Total axonal length & $55.8 \pm 8.2$ & $35.9 \pm 2.4$ & $97.1 \pm 1.4$ & $51.4 \pm 14.5$ \\
\hline Rostral flank (mean axonal length) & $15.4 \pm 2.7$ & $12.6 \pm 1.7$ & $51.4 \pm 4.9$ & $8.3 \pm 2.9$ \\
\hline Caudal flank (mean axonal length) & $18.7 \pm 3.2$ & $5.9 \pm 1.1$ & $16.4 \pm 3.6$ & $21.8 \pm 6.7$ \\
\hline PNP (mean axonal length) & $21.8 \pm 2.9$ & $17.4 \pm 0.6$ & $29.3 \pm 5.7$ & $21.3 \pm 5.4$ \\
\hline Rostrocaudal width (at $50 \%$ of peak) & $1.1 \pm 0.09$ & $0.7 \pm 0.07$ & $1.1 \pm 0.07$ & $1.0 \pm 0.1$ \\
\hline $\begin{array}{l}\text { Weighted average* (rostrocaudal location } \\
\text { relative to injection site) }\end{array}$ & $70 \pm 36$ & $-107 \pm 34$ & $-246 \pm 54$ & $195 \pm 72$ \\
\hline
\end{tabular}

Values in millimeters \pm SEM $(*$ is in micrometers \pm SEM $)$. 
to the results presented here, the normal isthmotectal connections are preserved (Udin and Keating, 1981), although they are not expressed physiologically. Responses mediated by these connections can be unmasked by acute removal of the rotated eye, suggesting that these nonadaptive responses are actively suppressed (Brickley et al., 1994). The mechanism of this suppression is not known.

\section{Comparison with retrograde labeling results}

Our results are in good agreement with those reported by Feldman and Knudsen (1997), who used retrograde techniques to investigate prism-induced anatomical plasticity. There are two differences, both of which can be explained by assuming that activity-dependent uptake and/or transport of retrograde tracers prevents the full visualization of axonal projections. First, there was evidence in the retrograde study that connections on the nonadaptive flanks decreased from juveniles to prism-reared adults, although this effect was not dramatic. Our anterograde results do not support this conclusion for rostrally directed shifts. Second, the elimination of caudal axons during normal development, which we describe, was not observed in the retrograde study, although a trend toward greater labeling in the juvenile was noted. Thus, the implications of the transition from a symmetrical juvenile pattern to an asymmetrical adult pattern were not appreciated with the retrograde technique. In all other respects, however, the results from both studies are very similar.

\section{REFERENCES}

Antonini A, Stryker MP (1993) Rapid remodeling of axonal arbors in the visual cortex. Science 260:1819-1821.

Antonini A, Stryker MP (1996) Plasticity of geniculocortical afferents after brief or prolonged monocular occlusion in the cat. J Comp Neurol 369:64-82.

Antonini A, Stryker MP (1998) Effect of sensory disuse on geniculate afferents to cat visual cortex. Vis Neurosci 15:401-409.

Brainard MS, Knudsen EI (1993) Experience-dependent plasticity in the inferior colliculus: a site for visual calibration of the neural representation of auditory space in the barn owl. J Neurosci 13:4589-4608.

Brickley SG, Keating MJ, Grant S (1994) Experience-dependent mechanism of binocular map plasticity in Xenopus: incongruent connections are masked by retinal input. Neurosci Lett 182:13-16.

Buonomano DV, Merzenich MM (1998) Cortical plasticity: from synapses to maps. Annu Rev Neurosci 21:149-186.

Darian-Smith C, Gilbert CD (1994) Axonal sprouting accompanies functional reorganization in adult cat striate cortex. Nature 368:737-740.

Feldman DE, Knudsen EI (1997) An anatomical basis for visual calibration of the auditory space map in the barn owl's midbrain. J Neurosci 17:6820-6837.

Florence SL, Kaas JH (1995) Large-scale reorganization at multiple levels of the somatosensory pathway follows therapeutic amputation of the hand in monkeys. J Neurosci 15:8083-8095.

Gold JI, Knudsen EI (2000) A site of auditory experience-dependent plasticity in the neural representation of auditory space in the barn owl's inferior colliculus. J Neurosci 20:3469-3486.
Guo Y, Udin S (2000) The development of abnormal axon trajectories after rotation of one eye in Xenopus. J Neurosci 20:4189-4197.

Holtzman E, Freeman AR, Kashner LA (1971) Stimulation-dependent alterations in peroxidase uptake at lobster neuromuscular junctions. Science 173:733-736.

Hyde PS, Knudsen EI (2000) Topographic projection from the optic tectum to the auditory space map in the inferior colliculus of the barn owl. J Comp Neurol 421:146-160.

Jiang X, Johnson RR, Burkhalter A (1993) Visualization of dendritic morphology of cortical projection neurons by retrograde axonal tracing. J Neurosci Methods 50:45-60.

King AJ, Hutchings ME, Moore DR, Blakemore C (1988) Developmental plasticity in the visual and auditory representations in the mammalian superior colliculus. Nature 332:73-76.

Kitt CA, Levy AI, Friedman DP, Walker LC, Koliatos VE, Raskin LS, Price DL (1988) Immunocytochemical visualization of cholinergic fibers in monkey: enhanced visualization using silver nitrate. Soc Neurosci Abstr 14:631.

Knudsen EI (1983) Early auditory experience aligns the auditory map of space in the optic tectum of the barn owl. Science 222:939-942.

Knudsen EI (1994) Supervised learning in the brain. J Neurosci 14:3985-3997.

Knudsen EI (1998) Capacity for plasticity in the adult owl auditory system expanded by juvenile experience. Science 279:1531-1533.

Knudsen EI, Brainard MS (1991) Visual instruction of the neural map of auditory space in the developing optic tectum. Science 253:85-87.

Knudsen EI, Knudsen PF (1983) Space-mapped auditory projections from the inferior colliculus to the optic tectum in the barn owl (Tyto alba). J Comp Neurol 218:187-196.

Knudsen EI, Knudsen PF (1990) Sensitive and critical periods for visual calibration of sound localization by barn owls. J Neurosci 10:222-232.

Knudsen EI, Knudsen PF, Masino T (1993) Parallel pathways mediating both sound localization and gaze control in the forebrain and midbrain of the barn owl. J Neurosci 13:2837-2852.

LeVay S, Stryker MP (1979) Society for neuroscience symposia: aspects of developmental neurobiology. Bethesda, MD: Society for Neuroscience.

Moiseff A, Konishi M (1981) Neuronal and behavioral sensitivity to binaural time differences in the owl. J Neurosci 1:40-48.

Olsen JF, Knudsen EI, Esterly SD (1989) Neural maps of interaural time and intensity differences in the optic tectum of the barn owl. J Neurosci 9:2591-2605.

Shatz CJ, Stryker MP (1978) Ocular dominance in layer IV of the cat's visual cortex and the effects of monocular deprivation. J Physiol (Lond) 281:267-283.

Somogyi P, Priestley JV, Cuello AC, Smith AD, Takagi H (1982) Synaptic connections of enkephalin-immunoreactive nerve terminals in the neostriatum: a correlated light and electron microscopic study. J Neurocytol 11:779-807.

Stein BE, Meredith MA (1993) The merging of the senses. Cambridge, MA: MIT.

Takahashi TT, Carr CE, Brecha N, Konishi M (1987) Calcium binding protein-like immunoreactivity labels the terminal field of nucleus laminaris of the barn owl. J Neurosci 7:1843-1856.

Udin SB, Grant S (1999) Plasticity in the tectum of Xenopus laevis: binocular maps. Prog Neurobiol 59:81-106.

Udin SB, Keating MJ (1981) Plasticity in a central nervous pathway in Xenopus: anatomical changes in the isthmotectal projection after larval eye rotation. J Comp Neurol 203:575-594.

Wagner H, Takahashi T, Konishi M (1987) Representation of interaural time difference in the central nucleus of the barn owl's inferior colliculus. J Neurosci 7:3105-3116.

Zheng W, Knudsen EI (1999) Functional selection of adaptive auditory space map by GABAA-mediated inhibition. Science 284:962-965. 